\title{
Topotaxial reactions during the genesis of oriented rutile/hematite intergrowths from Mwinilunga (Zambia)
}

\author{
Aleksander Rečnik • Nadežda Stanković • Nina Daneu
}

Received: 25 July 2014 / Accepted: 7 January 2015 / Published online: 6 February 2015

(C) The Author(s) 2015. This article is published with open access at Springerlink.com

\begin{abstract}
Oriented rutile/hematite intergrowths from Mwinilunga in Zambia were investigated by electron microscopy methods in order to resolve the complex sequence of topotaxial reactions. The specimens are composed of up to several-centimeter-large euhedral hematite crystals covered by epitaxially grown reticulated rutile networks. Following a top-down analytical approach, the samples were studied from their macroscopic crystallographic features down to subnanometer-scale analysis of phase compositions and occurring interfaces. Already, a simple morphological analysis indicates that rutile and hematite are met near the $\langle 010\rangle_{R}\{101\}_{R}||\langle 001\rangle_{H}\{110\}_{H}$ orientation relationship. However, a more detailed structural analysis of rutile/hematite interfaces using electron diffraction and high-resolution transmission electron microscopy (HRTEM) has shown that the actual relationship between the rutile and hosting hematite is in fact $\langle 010\rangle_{R}\{401\}_{R}||\langle 001\rangle_{H}\{170\}_{H}$. The intergrowth is dictated by the formation of $\{170\}_{H} \mid\{401\}_{R}$ equilibrium interfaces leading to 12 possible directions of rutile exsolution within a hematite matrix and 144 different incidences between the intergrown rutile crystals. Analyzing the potential rutile-rutile interfaces, these could be classified into four classes: (1) non-crystallographic contacts at $60^{\circ}$ and $120^{\circ},(2)$ $\{101\}$ twins with incidence angles of $114.44^{\circ}$ and their complementaries at $65.56^{\circ}$, (3) $\{301\}$ twins at $54.44^{\circ}$ with complementaries at $125.56^{\circ}$ and (4) low-angle tilt boundaries at $174.44^{\circ}$ and $5.56^{\circ}$. Except for non-crystallographic contacts, all other rutile-rutile interfaces were confirmed in Mwinilunga
\end{abstract}

Communicated by Chris Ballhaus.

A. Rečnik $(\bowtie) \cdot$ N. Stanković $\cdot$ N. Daneu

Department for Nanostructured Materials, Jožef Stefan Institute,

Jamova Cesta 39, 1000 Ljubljana, Slovenia

e-mail: aleksander.recnik@ijs.si samples. Using a HRTEM and high-angle annular dark-field scanning TEM methods combined with energy-dispersive $\mathrm{X}$-ray spectroscopy, we identified remnants of ilmenite lamellae in the vicinity of rutile exsolutions, which were an important indication of the high-T formation of the primary ferrian-ilmenite crystals. Another type of exsolution process was observed in rutile crystals, where hematite precipitates topotaxially exsolved from Fe-rich parts of rutile through intermediate Guinier-Preston zones, characterized by tripling the $\{101\}$ rutile reflections. Unlike rutile exsolutions in hematite, hematite exsolutions in rutile form $\{301\}_{R} \mid\{030\}_{H}$ equilibrium interfaces. The overall composition of our samples indicates that the ratio between ilmenite and hematite in parent ferrianilmenite crystals was close to $\mathrm{Ilm}_{67} \mathrm{Hem}_{33}$, typical for Fe-Tirich differentiates of mafic magma. The presence of ilmenite lamellae indicates that the primary solid solution passed the miscibility gap at $\sim 900{ }^{\circ} \mathrm{C}$. Subsequent exsolution processes were triggered by surface oxidation of ferrous iron and remobilization of cations within the common oxygen sublattice. Based on nanostructural analysis of the samples, we identified three successive exsolution processes: (1) exsolution of ilmenite lamellae from the primary ferrian-ilmenite crystals, (2) exsolution of rutile lamellae from ilmenite and (3) exsolution of hematite precipitates from Fe-rich rutile lamellae. All observed topotaxial reactions appear to be a combined function of temperature and oxygen fugacity, $\mathrm{fO}_{2}$.

Keywords Ilmenite $\cdot$ Hematite $\cdot$ Rutile $\cdot$ Topotaxy Exsolution · Intergrowth $\cdot$ Geothermometer

\section{Introduction}

Various intergrowths of rutile with structurally related minerals are known in nature. They are found in igneous and 
metamorphic rocks (Force et al. 1996) and form either as a result of topotaxial replacement reactions through decomposition of Ti-rich minerals or by epitaxial growth of rutile on structurally related mineral precursors. Out of these, the most spectacular are rutile/hematite overgrowths, forming splendid, up to several-centimeter-large crystals clusters, mutually linked through well-defined orientation relationships (Armbruster 1981). The final product of these replacement processes is rutile forming reticulated sagenite networks where individual crystals are interconnected through complex crystallographic laws.

The most common precursors for the rutile/hematite intergrowths are members of the ilmenite-hematite tie-line in $\mathrm{FeO}-\mathrm{TiO}_{2}-\mathrm{Fe}_{2} \mathrm{O}_{3}$ ternary system. The phase composition in this system depends on the $\mathrm{Fe}-\mathrm{Ti}$ ratio, temperature and oxygen fugacity, $f \mathrm{O}_{2}$, while the effect of pressure is less important (Buddington and Lindsley 1964; Lindh 1972). At the elevated temperatures, the compounds on the rhombohedral (ilm-hem) tie-line form a complete solid solution, while at lower temperatures they become immiscible, and depending on the amount of $\mathrm{Fe}^{3+}$, they separate into exsolutions of hematite in ilmenite host or ilmenite in hematite host (Lindsley 1973; Ghiorso 1990; Lindsley 1991; McEnroe et al. 2005). In nature, there are many examples of lamellar intergrowths of hematite and ilmenite from microscopic grains in igneous and metamorphic rocks to large macroscopic crystals in pegmatite differentiates of mafic to ultramafic magmas (Ramdohr 1969; Haggerty 1971). On cooling, the activity of oxygen is increased and ilmenite may oxidize to hematite and rutile (Carmichael and Nichols 1967; Zhao et al. 1999). Understanding the transient stages of phase transformations in this system is important in geothermometry research (Burton 1985; Harrison et al. 2000; Meinhold 2010).

The formation of oriented intergrowths is commonly explained by topotaxial transformation of the precursor phase into reaction products along specific crystallographic orientations (Dent Glasser et al. 1962). Such reactions can only occur among structurally related minerals, such as hematite, ilmenite and rutile. These minerals are related through a common hexagonal close-packed (hcp) oxygen sublattice that extends along the basal planes of the corundum-type structure (e.g., hematite, ilmenite) and $a$ or $b$ planes of rutile. In rhombohedral ilmenite $(R \overline{3})$ and hematite $(R \overline{3} c)$, the arrays of oxygen atoms in basal planes intersect at $60^{\circ}$, whereas in rutile structure they are regularly spaced along the $c$ direction and slightly compressed along $a$ and $b$ directions. This gives rise to tetragonal distortion of the rutile's oxygen sublattice yielding the angles of $57.22^{\circ}$ between $\langle 101\rangle$ and $\langle 001\rangle$, and $65.56^{\circ}$ between $\langle 101\rangle$ and $\langle\overline{1} 01\rangle$. This deviation from an ideal hexagonal packing of oxygen atoms has an important influence on the rutile exsolution mechanisms and is the main reason for generation of crystallographically different intergrowths. Studying morphological characteristics of rutile intergrowths with different structurally related oxides, Armbruster (1981) also described two possible orientation relationships (ORs) of rutile with the corundum-type structure. Figure 1 shows the two ORs, where three equivalent $\langle 210\rangle_{H}$ oxygen arrays are aligned either parallel to $\langle 001\rangle_{R}$ (Fig. 1a) or one of the $\langle 101\rangle_{R}$ (Fig. 1b) axes of rutile (laws IV and V; Armbruster 1981):

OR-1: $\langle 001\rangle_{R}\{010\}_{R} \|\langle 210\rangle_{H}\{001\}_{H}$

OR-2: $\langle 101\rangle_{R}\{010\}_{R} \|\langle 210\rangle_{H}\{001\}_{H}$

OR-1 is the most simple of the two laws. Rutile exsolutions according to this law intersect simply at $60^{\circ}$ or $120^{\circ}$. These angles, however, produce non-crystallographic junctions between the rutile crystals. Crystallographic relations between the rutile crystals exsoluted following OR-2, on the other hand, are more complex, but form well-defined crystallographic junctions corresponding to known special boundaries in rutile; e.g., $54.4^{\circ}$ for $\{301\}$ twin and $114.4^{\circ}$ for $\{101\}$ twin. Armbruster (1981) described several examples of intergrowths as observed on natural as well as synthetic rutile crystals. Depending on the formation conditions $(p-T$, geochemical environment), they follow either of the two laws. Force et al. (1996) reported OR-1 when describing the exsolutions of rutile in ilmenite, while crystallographic junctions corresponding to OR-2 are formed exclusively by growth twinning. They also suggested that the angles between the rutile domains can be used as the criterion to distinguish between topotaxial transformations and growth twinning in rutile. Recent investigations of $\{101\}$ and $\{301\}$ rutile twins from Diamantina in Brazil revealed that they also form by topotaxial replacement of Al-rich $\mathrm{Fe}-\mathrm{Ti}$ oxyhydroxide precursors with the tivanite-type structure (Daneu et al. 2007, 2014). It has been demonstrated that topotaxial reactions result in the formation of well-defined crystallographic junctions between the rutile domains according to OR-2, forming complex sagenite intergrowths. The twin boundaries were shown to accommodate remnants of dehydrated precursors, i.e., precipitates of corundum on (101) twin boundaries and few nanometer-thick lamellae of Al-rich ilmenite on (301) twin boundaries.

In the majority of previous works on mineralogical samples, determination of OR between the rutile and the precursor minerals relies upon morphology and macroscopic features, such as the angles between the adjacent rutile domains (Ramdohr 1969; Armbruster 1981; Force et al. 1996). If the angles are measured by non-crystallographic means (from micrographs), their determination may vary in excess of $2.78^{\circ}$, which is the angle that allows to differentiate the two ORs along the threefold $c$-axis of the host. This 


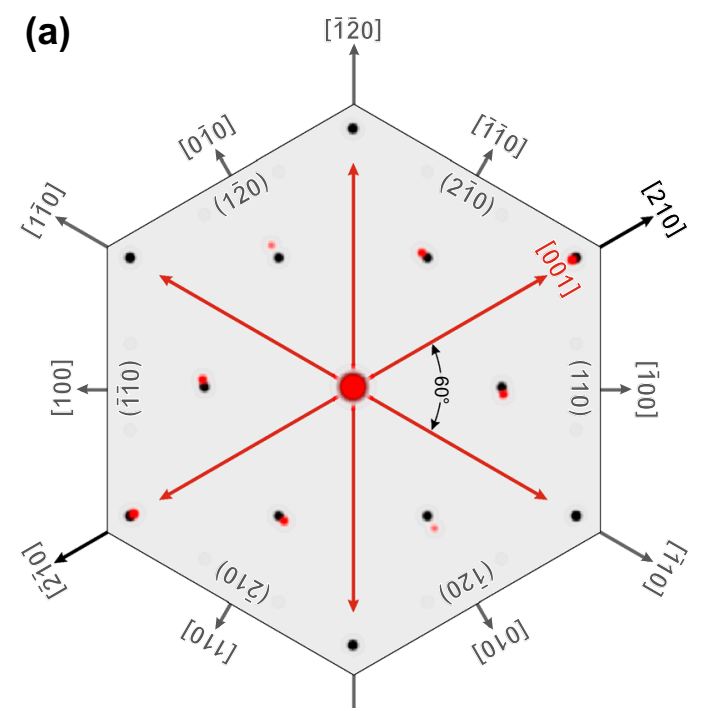

OR-1: $\langle 001\rangle_{R}\{010\}_{R} \|\langle 210\rangle_{H}\{001\}_{H}$

Fig. 1 Schematic presentation of two orientation relationships (ORs) between hematite (black) and rutile (red), according to Armbruster (1981). a In rutile exsolutions following the OR-1, the $c$-axes of rutile crystals $\langle 001\rangle$ are parallel to the $\langle 210\rangle$ directions of hematite resulting in three orientations of rutile, intersected at $60^{\circ}$. b In OR-2, however, the $\langle 101\rangle$ directions in rutile are brought parallel to the $\langle 210\rangle$ direc-

appears to be the main reason for the conflicting reports on actual ORs in minerals (Force et al. 1996). TEM investigations of hematite exsolution from Fe-rich rutile have shown that their OR strongly depends on the formation conditions (Putnis 1978). Minimization of interfacial energy at the given formation condition was proposed as the main mechanism for establishing a particular OR (Hwang et al. 2010) and could be held responsible for different ORs that were observed on rutile/hematite intergrowths (Armbruster 1981).

In our work, we studied oriented rutile/hematite intergrowths from Mwinilunga in Zambia. The specimens occur in form of large hematite crystals covered by well-crystallized rutiles frequently displaying $\{101\}$ twin junctions on their surface. The specimens from this locality show complex crystallographic dependencies between the overgrown rutiles and the still existing hematite matrix. They were selected for studying the initial stages of topotaxial reactions, which are usually not preserved at other localities where only sagenitic rutile remains as the end product of the transformation processes. The main tool for our investigation is methods of transmission electron microscopy (TEM), which allow reliable determination of ORs and study transient processes, frozen in the hosting structure at the subnanometer scale. Chemical and structural information will be used to reconstruct the formation of oriented rutile/hematite intergrowths.

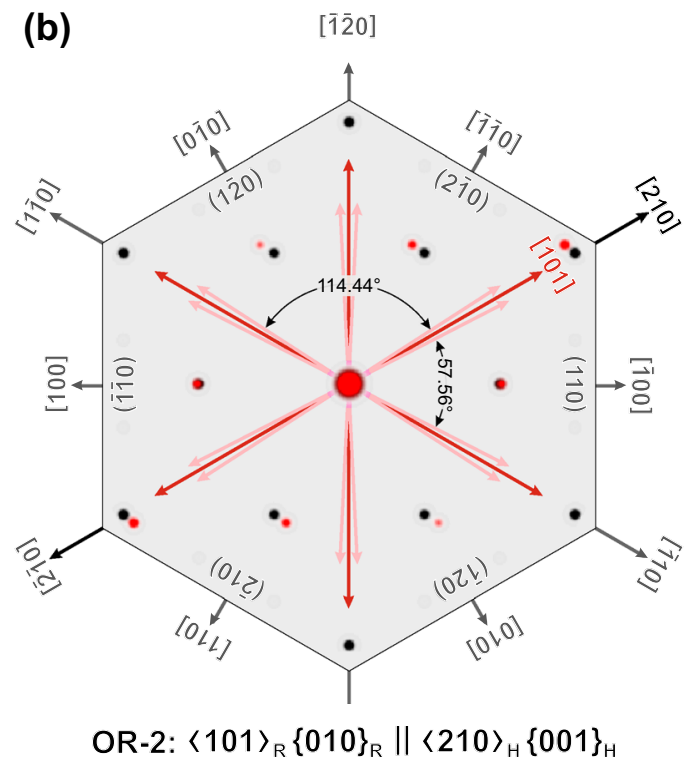

tions of hematite, and consequently, the $c$-axes of rutiles are misaligned for $2.78^{\circ}$ away from $\langle 210\rangle$-type directions of hematite. Rutiles exsolved according to this law exhibit different crystallographic junctions, listed in Table 1, among which the well-known $\{101\}$ and $\{301\}$ twin boundaries are commonly observed

\section{Specimen description}

Rutile/hematite intergrowths originating from Mwinilunga area in NW Zambia occur in impressive clusters composed of several-centimeter-large tabular hematite crystals with up to few millimeters large deep-red rutiles perched on their basal surfaces. Already, a simple visual inspection of glittering rutile faces reveals that the rutiles are in a welldefined crystallographic relation with the parent hematite crystal. Orientation relationships between rutile and hematite are shown in Fig. 2.

The most prominent feature of rutiles is their jagged appearance parallel to crystallographic $c$-axes, which results from alternation of rutile's prism faces. This alternation makes fine-structural features between the rutile crystals clearly visible. Rutiles grown on the basal surfaces of hematite crystals display complex knee twinning produced by combinations of $\{101\}$ (Daneu et al. 2014) and \{301\} twins (Daneu et al. 2007). The twin boundaries are easily identified by characteristic angles between the crystallographic $c$-axes (114.7 and $54.7^{\circ}$, respectively). These angles can be measured only when the twinned crystals are oriented exactly along their $b$-axis, and this condition is met when the parent hematite is viewed from the top, i.e., along its $c$-axis. This rule appears to hold for all rutile crystals. In addition to twin relations other, yet unknown, intergrowth structures are present among the rutile crystals. In fact, all the rutiles 


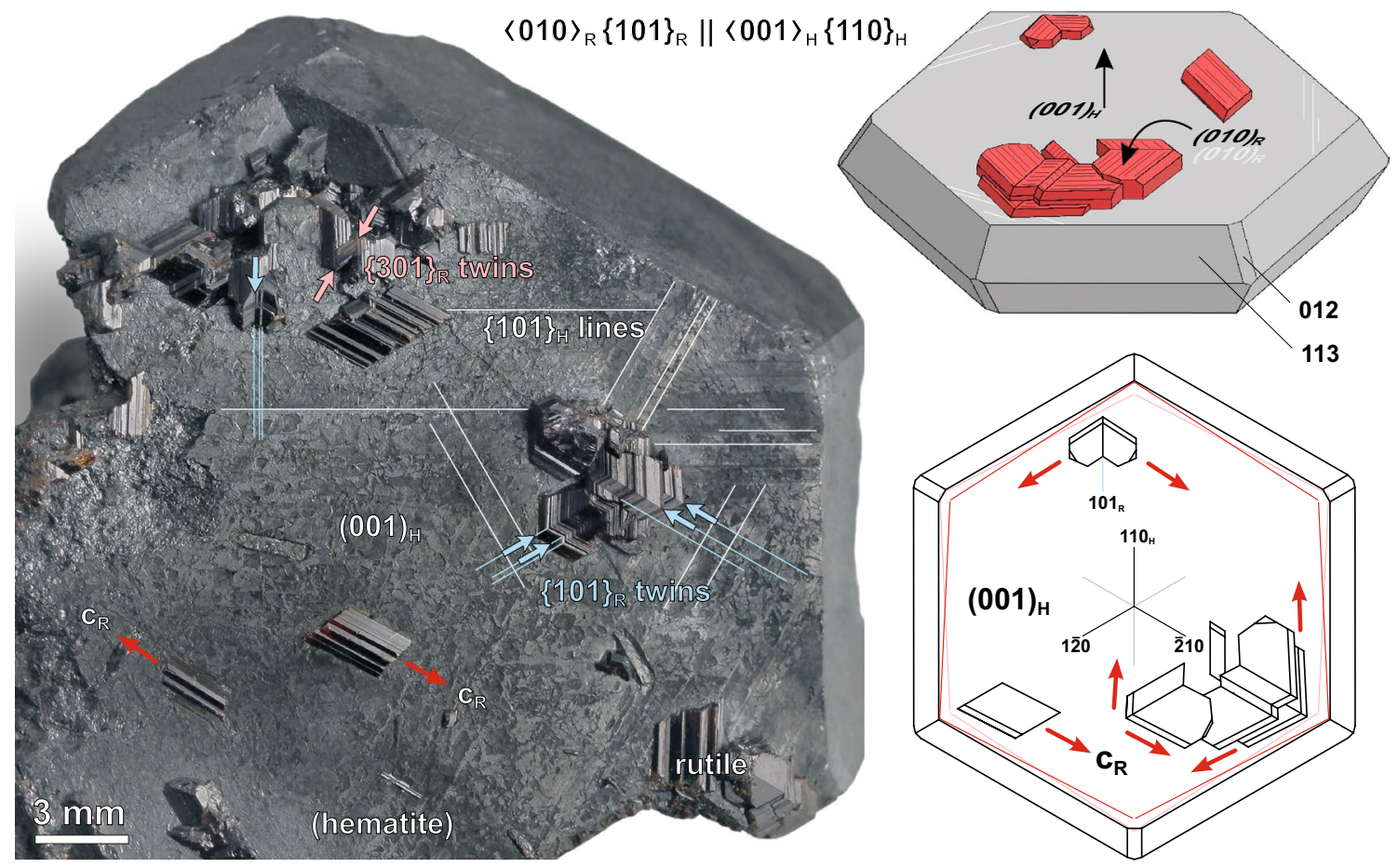

Fig. 2 Oriented overgrowth of rutile on hematite crystal from Mwinilunga, Zambia. Distinct morphology of the parent crystal can be used for the determination of crystallographic relations between the rutile and hematite. The basal surface of hematite is crosshatched by etch figures along the $\{101\}_{\mathrm{H}}$ facets (indicated as thin white lines, intersecting at $60^{\circ}$ ). These lines run perpendicular to the crystal edges of hematite. While $c$-axes of rutile do not seem to coincide with any low-index features in hematite, $\{101\}$ planes of rutile (twin boundaries, indicated by blue arrows on the photograph) are matching $\{110\}$ planes of hematite (parallel to the crystal edges). In addition, $b$ (or

are grown in some salient topotaxial connectivity dictated by hosting hematite. The morphology of hematite is helpful to resolve these crystallographic relations. While the $c$-axes of rutile crystals are tilted for $\sim 3^{\circ}$ from the edges of the parent hematite, we will observe that $\{101\}$ twin boundaries of rutile are oriented exactly perpendicular to the $\{100\}_{H}$ planes of hematite, visible as grooves, resulting from alternation of $\{101\}_{H}$ with $\{001\}_{H}$ planes. Crystallographic relation based on macroscopic features of rutile/hematite intergrowths corresponds to OR-2, written in terms of $\langle 001\rangle_{H}$ projection, more suitable for our crystallographic analysis:

OR-2: $\langle 010\rangle_{R}\{101\}_{R}||\langle 001\rangle_{H}\{110\}_{H}$

More strictly, this general relation holds for three exclusive conditions: (a) $\langle 010\rangle_{R}\{101\}_{R} \|[001]_{H}(110)_{H}$, (b) $\langle 010\rangle_{R}\{101\}_{R} \|[001]_{H}(1 \overline{2} 0)_{H}$, and (c) $\langle 010\rangle_{R}\{101\}_{R} \|$ $[001]_{H}(\overline{2} 10)_{H}$. Namely, the four $\{101\}_{R}$ planes of the first set of rutile orientations that are bound to a chosen $(110)_{H}$ plane in OR- $2 a$ are at the same time not parallel to $(1 \overline{2}$ $0)_{H}$ and $(\overline{2} 10)_{H}$ planes from relations OR- $2 b$ and OR- $2 c$, a)-axis of all rutile crystals is aligned parallel to the $c$-axis of hematite (see the 3D drawing of hematite crystal with epitaxial rutiles). Hence, the following orientation relationship between rutile and hematite can be deduced: $\langle 010\rangle_{R}\{101\}_{R} \|\langle 001\rangle_{H}\{110\}_{H}$. The observed crystallographic relations between the hematite and rutile are illustrated next to the photograph. Note that $\{101\}_{R}$ twin boundaries (top view) are lined up with $\{110\}_{H}$ planes of parent hematite. Thin red lines at the edges of the hematite crystal indicate all possible $c$-axes orientations of epitaxial rutiles, while red arrow indicates $c$-axes of individual rutile crystals

respectively. This sums up to 12 unique in-plane orientations (i.e., six $\pm c$-axis pairs) of rutile crystals on hematite, indicated by the thin red lines in the top-view illustration of Fig. 2. It is quite interesting that the $c$-axes of rutiles do not match any low-index direction of the parent hematite crystal, and yet, the two minerals are found in such a welldefined orientation relationship. In the following, microscopy methods are used to determine the exact structural relations brought by topotaxial growth of rutile on hematite.

\section{Analytical methods}

To resolve complex crystallographic relations, the samples were studied in two orientations, in-plane $(001)_{H}$ and perpendicular $(100)_{H}$, by optical, scanning (SEM) and transmission electron microscopy (TEM) methods combined with energy-dispersive X-ray spectroscopy (EDS). Phase composition of the samples was determined by powder $\mathrm{X}$-ray diffraction $(\mathrm{XRD})$. 
X-ray diffraction analysis

The interior sections of rutile/hematite samples were first examined for bulk phase composition. The samples were crushed in an agate mortar and analyzed by X-ray powder diffractometer (PW1710, Philips GmbH, Germany) using a Ni-filtered $\mathrm{Cu}-\mathrm{K} \alpha$ radiation in the range $2 \theta=10-80^{\circ}$ with a step of $0.02^{\circ}$ and recording time of $0.5 \mathrm{~s} / \mathrm{step}$. Raw diffractograms were matched by crystallographic data for rutile (ICSD-63710), hematite (ICSD-15840) and ilmenite (ICSD-30664).

\section{Optical microscopy}

A few-mm-thin segments were cut in two orientations from the center of the samples in both orientations, glued on the glass substrate, thinned to about $10 \mu \mathrm{m}$ and finally polished by $1 / 4 \mu \mathrm{m}$ diamond paste. While hematite is optically opaque, strong birefringence of rutile could be used to investigate extinctions between twin domains under polarized light. Thin sections of the samples were studied using a polarized light source and photographic camera equipped with macro-objective lens and polarizing filter (Canon 500D, Japan). Details of the samples were further investigated using a petrographic microscope (Axio Imager Z1m, Carl Zeiss Microscopy GmbH, Jena, Germany).

\section{Scanning electron microscopy}

Intergrowth of minerals, their morphology and chemical composition of the samples were additionally studied by SEM (JSM-5800, Jeol Ltd., Tokyo, Japan) operated at $20 \mathrm{kV}$ and equipped with EDS (Model 6841, Oxford Instruments, Oxfordshire, UK) for elemental analysis. Using SEM, the surfaces of the samples and their cross sections were investigated. The samples were sputtered by a thin layer of carbon to produce surface conductivity necessary for SEM observations and EDS analysis.

\section{Transmission electron microscopy}

To study the transient topotaxial processes and evolution of rutile and hematite intergrowths, thin slices were cut in two perpendicular low-index, basal $(001)_{H}$ and prismatic $(100)_{H}$ orientations, and searched for locations showing complex intergrowth structures under the optical microscope. Selected areas of interest were drilled by ultrasonic cutter (SoniCut 380, South Bay Technology Inc., San Clemente, California) into a 3-mm-diameter disks for TEM investigations. While keeping the selected feature near the disk center, the samples were mechanically ground from both sides down to the thickness of $\sim 100 \mu \mathrm{m}$. The disks were then polished and dimpled (Dimple grinder 656, Gatan Inc.,
Pleasanton, California) from one side down to $\sim 20 \mu \mathrm{m}$ at the dimple center. Finally, the specimens were ion thinned from both sides using $4 \mathrm{kV} / 1.2 \mathrm{mV} \mathrm{Ar}^{+}$ions (PIPS 691, Gatan Inc.) at an incidence angle of $10^{\circ}$ until perforation to produce large electron-transparent areas in the peripheral part of the hole, suitable for TEM observations. For TEM studies, a conventional 200-kV TEM with an $\mathrm{LaB}_{6}$ electron source (JEM-2100, Jeol Ltd., Tokyo, Japan) and a 200-kV TEM/STEM with field emission gun (FEG) electron source (JEM-2010F, Jeol Ltd., Tokyo, Japan) equipped with Si(Li) energy-dispersive X-ray spectrometer (Link ISIS-300, Oxford Instruments, Oxfordshire, UK) and a high-angle annular dark-field detector (HAADF-STEM) were used. The point-to-point resolution of $\sim 0.19 \mathrm{~nm}$, achieved by FEG-TEM microscope, is sufficient for resolving $\{110\}_{H}$ lattice spacings $\left(d_{110_{H}}=0.2519 \mathrm{~nm}\right)$ in $[001]_{H}$ zone axis.

\section{Results}

The origin of rutile/hematite intergrowths was studied by a combination of microscopy and spectroscopy methods. From macroscopic epitaxial relations observed on the specimens (Fig. 2), the basic crystallographic orientation relationship between the rutile and hematite was deduced (OR2). To resolve other questions, as what is the equilibrium hematite/rutile interface, which are the energetically stable rutile-rutile interfaces, is there an internal source of Ti ions such as ilmenite, and finally, what triggers the hematite/ rutile phase separation, the samples need to be investigated at the atomic scale. To find answers to these questions, full structural analysis from microscopic down to the nanometer scale is performed.

Textural characteristics of rutile/hematite intergrowths

Figure 3 shows typical cross sections of the sample viewed along the $[001]_{H}$ orientation. Under polarized light, the rutile crystals appear in shades of red, brown, yellow and green, while the non-transparent hematite is black (Fig. 3a). In all samples, we observe that the rutile crystals near the surface are larger than in the interior of the matrix hematite crystal. Rutile is highly birefringent. In the incident wave of polarized light, its color strongly depends on crystal's orientation. In this orientation, the optical axis of rutile ( $c$-axis) lies normal to the incident light wave. In-plane rotation of the thin section thus shows regular extinctions of rutile domains at every $\sim 60^{\circ}$ with about $\pm 5^{\circ}$ shift from each set related to the twin pairs, whereby the angle measured between identical extinction conditions for a twin pair amounts to $\sim 114^{\circ}$, which corresponds to the characteristic angle between the $c$-axes of (101) twin in rutile. Most of the larger rutile domains appear to be linked by this relation. 

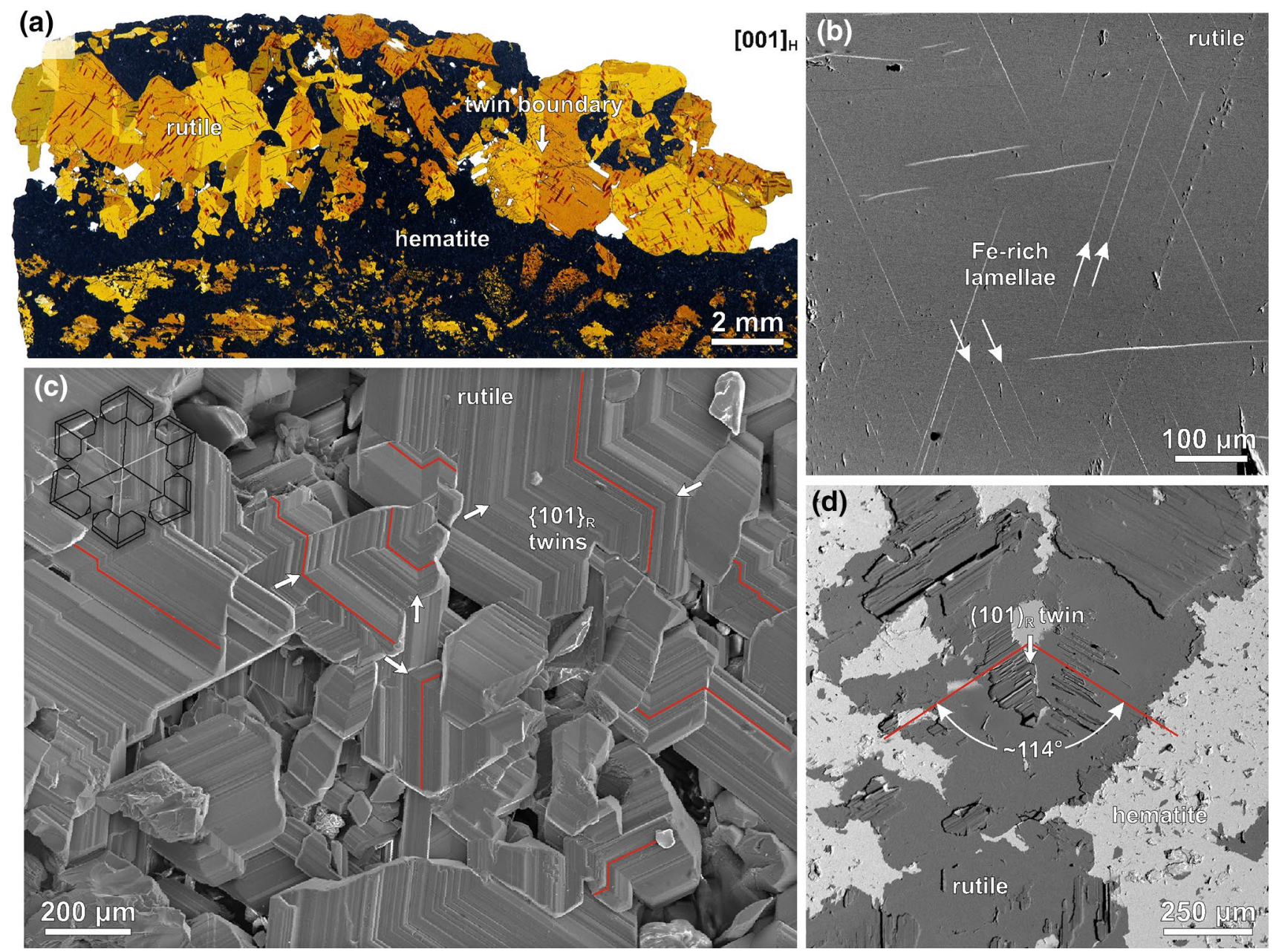

Fig. 3 Top view of rutile/hematite intergrowths; $[001]_{H}$ projection. a A thin section of the sample in polarized light. Black areas belong to non-transparent hematite matrix, whereas transparent domains colored in shades of yellow-orange-brown correspond to rutile. Red stripes within the rutile crystals indicate oriented exsolutions of a mineral with a deep-red pleochroism. b Hematite exsolutions in rutile indicated by arrows. $\mathbf{c}$ Secondary electron image of the recrystallized surface of the sample with well-developed rutile crystals. The rutiles show abundant $\{101\}$ twinning from simple contact, to parallel, and more complex cyclic twin combinations. Few twin boundaries are pointed out by arrows, whereas red lines delineate the $c$-axes of the crystals. The drawing in the upper left corner indicates possible primary twin orientations dictated by the underlying hematite crystal. d Backscattered electron image of polished cross section from the interior of the sample showing rutile domains in (101) twin relation embedded in hematite matrix
Another distinct feature that can be observed in most of the rutile domains are reddish stripes, which are running more or less parallel within a single rutile domain and are mirrored across the twin boundaries. Their red coloration suggests that these stripes may correspond to exsolutions of hematite. Our SEM/EDS analysis of the red stripes in rutile crystals (Fig. 3b) confirmed that they are Fe-rich. They appear in form of thin lamellae visible as bright lines in backscattered electron images. The angles between the lines are consistent throughout the hosting rutile crystal and suggest structurally driven exsolution of Fe-rich component to specific planes of rutile. In addition to these sharp exsolution lamellae, other more irregular exsolutions can be observed. Twinning of rutile is best seen on the $(001)_{H}$ surface of the sample (Fig. 3c). Here, rutiles form a characteristic in-plane arrangement of twinned crystals, known as sagenite networks. As already observed by light microscopy, most of the twins are of $\{101\}$ type with sharp and fairly long contact planes. Coarse crystallinity and a distinct morphology of the rutiles imply an abundant recrystallization, which happened on the free surfaces of the samples. While the central sections appear more compact, some porosity is present even in the interior of the samples as a result of leaching of the more soluble mineral components. Such situations are best seen in polished cross sections, where thin parts of material broke off and faceted surfaces of rutile, characterized by the alternating $\{110\}_{R}$ faces, are revealed (Fig. 3d). The appearance of rutiles in the interior 
(a)
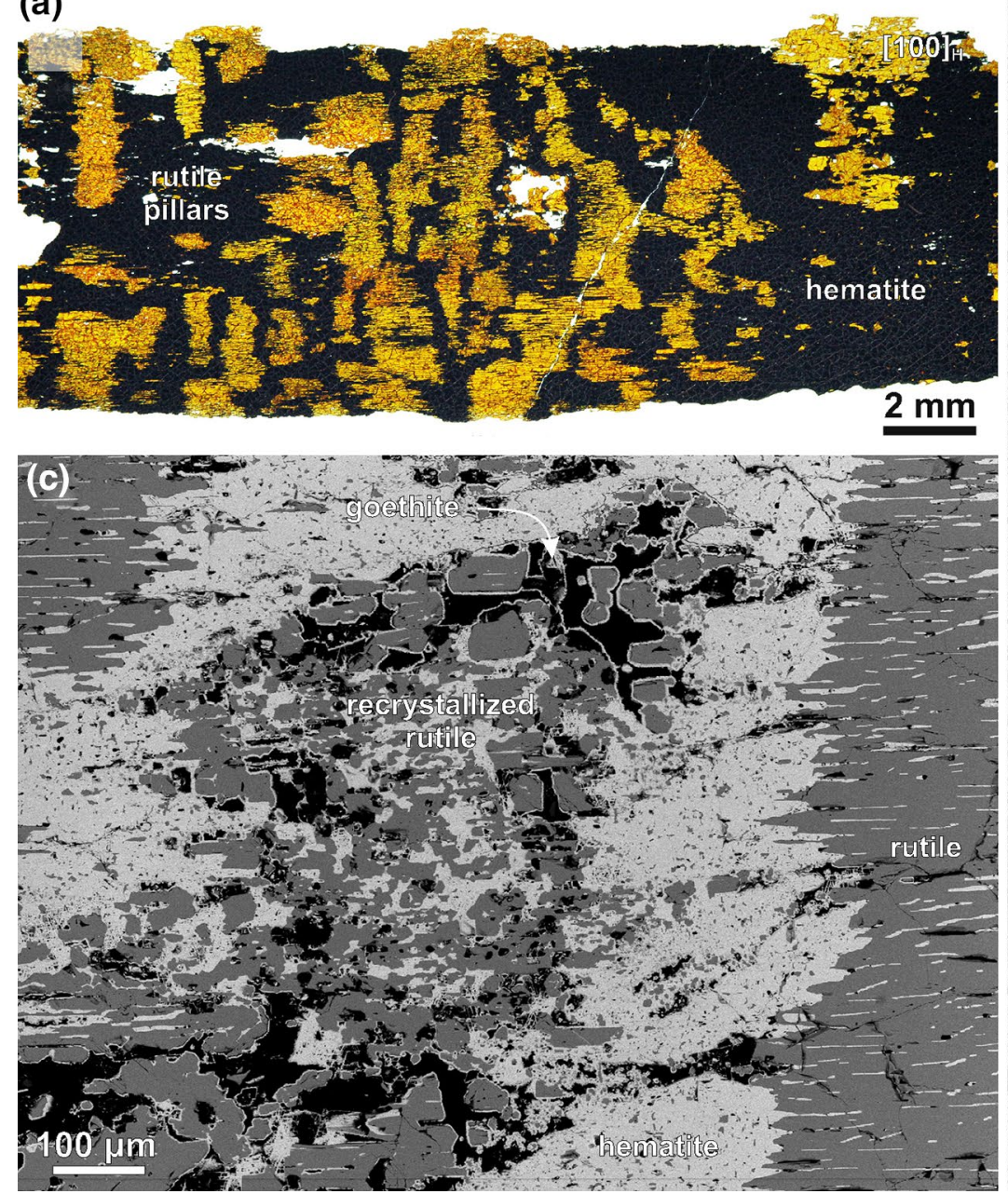

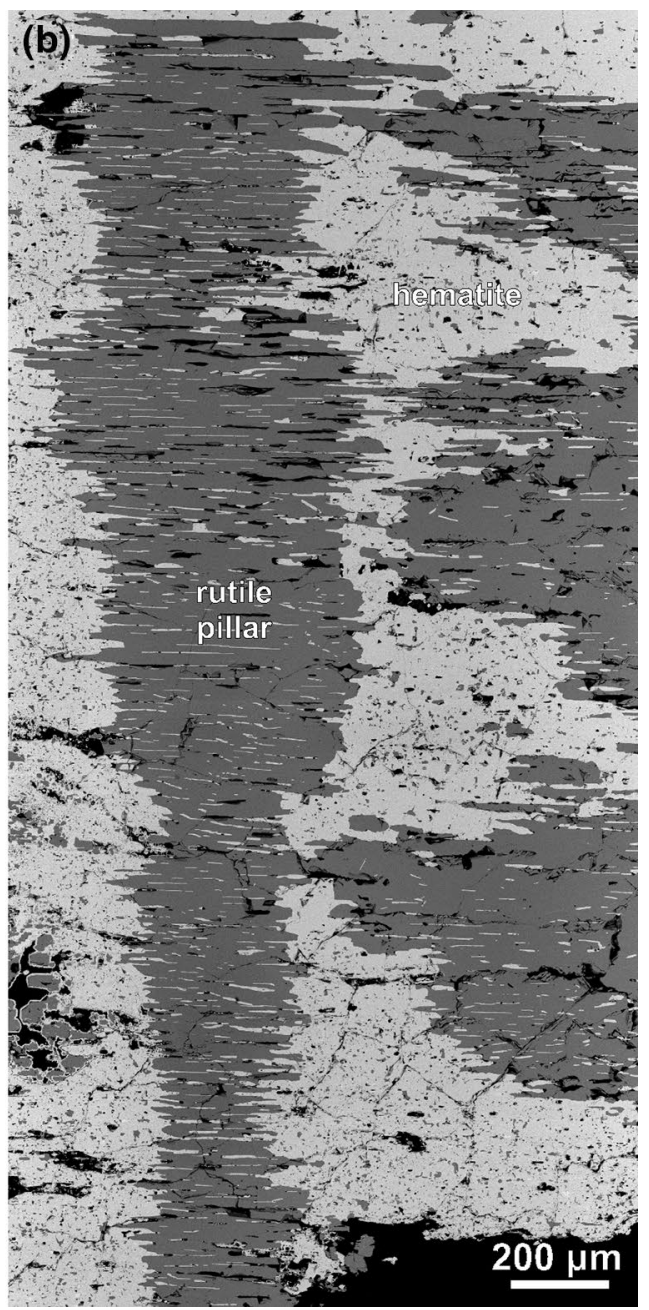

Fig. 4 Side view of rutile/hematite intergrowths; $[100]_{H}$ projection. a Cross section of the specimen with yellow-orange rutile pillars within the matrix of opaque hematite. Columnar rutile domains from the interior protrude all the way to the top (basal surface) of the hosting hematite crystal. b Backscattered SEM image of rutile pillar in hematite. In this view, $b$-axis of rutile is oriented roughly parallel to the vertical direction of the pillars. c Close-up of fresh (right side) and recrystallized (center) rutile pillar. Fresh pillars show little porosity and have sharp contacts with the hosting hematite. They are composed of thin rutile slabs, piled up into columns along its $b$-axis. In the recrystallized part, this texture is ruined. Here, hematite is leached out and replaced by idiomorphic rutile crystals covered by a crust of Fe-oxyhydroxides of the sample is different from those on the surface. They no longer show idiomorphic morphology, but are elongated along directions more or less parallel with $a$ (or $b$ )axes. This is quite uncommon for rutile, which without any outer restraints, shows preferential growth along the $c$-axis. The contact between the rutile and hematite is wavy, especially in the direction of the rutile's $c$-axis. Here and there, the neighboring rutile domains are brought into contacts, which do not appear to be a part of a primary exsolution process, but rather a consequence of rutile-domain growth. The ratio between rutile and hematite in the interior part of the samples close to 1:1 was determined from several SEM images recorded at low magnifications. SEM image in Fig. 3d shows two rutile domains met in $(101)_{R}$ twin orientation. Compared to the surface, the twin contacts are quite seldom in the interior of the samples and represent a rarity.

When the intergrowths are viewed in vertical cross section (Fig. 4), very different texture is observed. Here, the rutile domains form pillars composed of platy rutile crystals interwoven with the hosting hematite matrix. Some rutile pillars extend through the whole thickness of the hosting hematite crystal and protrude over the surface line (Fig. 4a). Typical thickness of individual rutile platelets is $\sim 20 \mu \mathrm{m}$, whereas their widths can span over several millimeters. They are closely packed and piled up along the crystallographic $b$-axis, based on the observed crystallographic relation between hematite and rutile (OR-2). Minor 

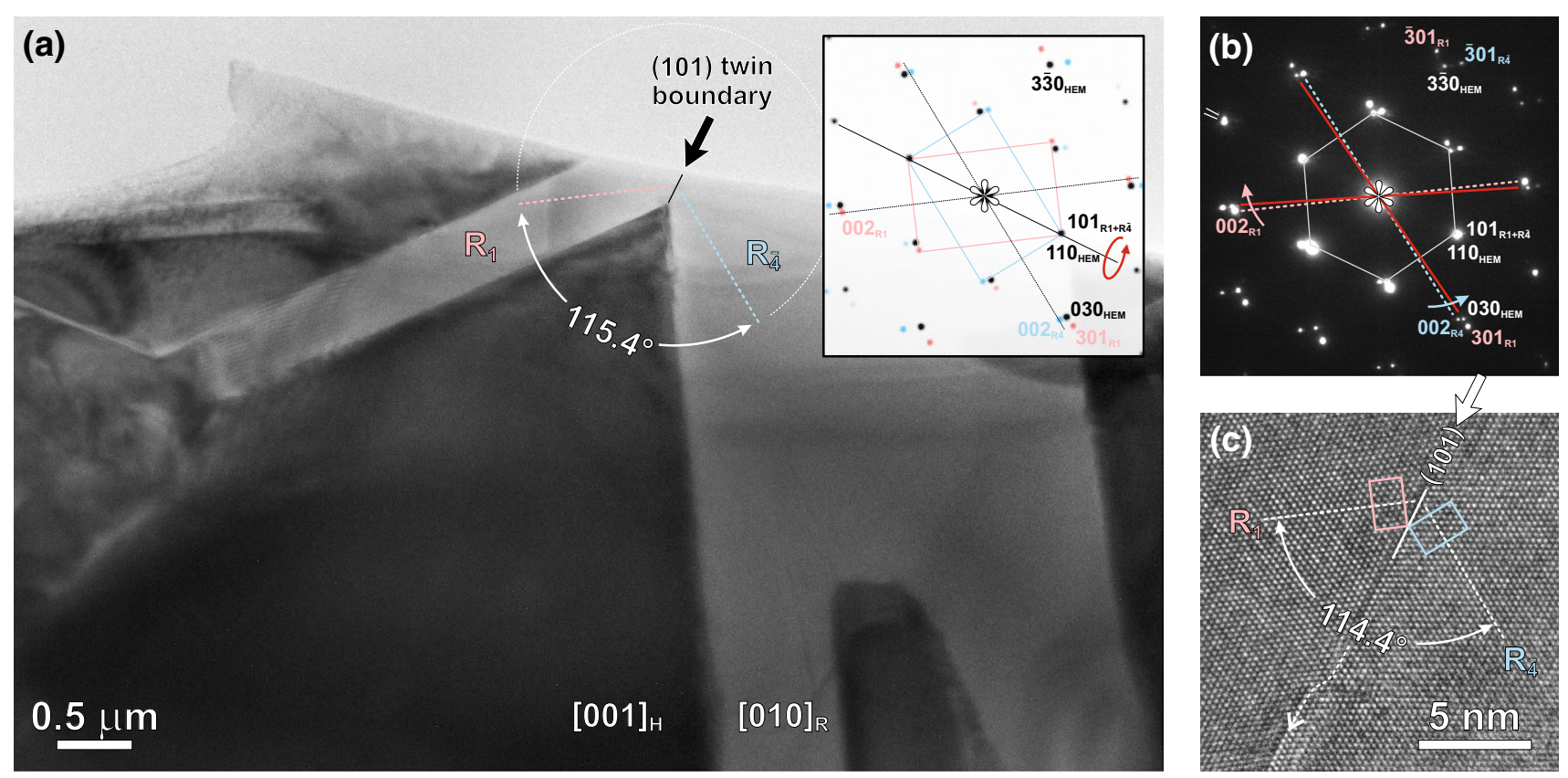

Fig. 5 Structural study of (101)-twin interface between two exsolution lamellae in hematite viewed along the $[001]_{H}$ zone axis. a Bright-field (BF) TEM image of rutile lamellae in hematite. b Electron diffraction pattern (EDP) from the area including hematite and both rutile domains shows that when hematite is in $[001]_{H}$ projection, all rutile domains are in $[010]_{R}$ orientation, according to OR-2. The angle between the $c$-axes of rutile domains $R_{1}$ (red) and $R_{\overline{4}}$ (blue) measured from EDP is $\sim 115.4^{\circ}$ (note the twist indicated by arrows). As a result, small splitting of the reflections related to the mirror plane can be observed. Simulated EDP in (a) is shown for comparison. c HRTEM image of the (101) interface with steps compensating for the orientation mismatch and sections with an ideal (101)-twin configuration with the angle between the $c$-axes of $114.4^{\circ}$

investigated by TEM. Rough inspection of several samples confirmed that the general orientation of the hematite matrix remains unchanged, regardless the presence of numerous rutile exsolutions. Complex hematite/rutile intergrowth structures are best viewed in $[001]_{H}$ projection. In this view, rutile lamellae are intersecting hosting hematite crystal in different angular directions, forming random topotaxial networks. As opposed to the specimen surface, twin boundaries in the interior of the sample appear to be fairly rare. Figure 5 shows one such situation where two rutile lamellae are coinciding in (101) twin orientation. At first glance, electron diffraction pattern (EDP) recorded from the area including hematite matrix and the twin boundary (Fig. 5a) suggests that the rutile domains are met in (101) twin orientation (diffraction spot doublets), and at the same time, they share a topotaxial relation with hosting hematite (Fig. 5b), according to OR-2. However, when we measure the angle between the $c$-axes of $R_{1}$ and $R_{\overline{4}}$ domains, it appears to be slightly larger than the angle typical for (101) twins in undistorted rutile. To explain this deviation, theoretical diffraction patterns for ideal hematite (Blake et al. 1966) and rutile (Howard et al. 1991) structures were calculated. They both match the reported values, producing characteristic triplets of correlated reflections, resulting from twinning of two rutile crystals and $1.2 \%$ 
difference between the $d_{(101) R}(0.2487 \mathrm{~nm})$ versus $d_{(110) H}$ $(0.2519 \mathrm{~nm})$ reflections. To understand experimental EDP, simulated pattern was composed of two rutile crystals in (101) twin orientation with a hematite crystal aligned into OR-2 (inset, Fig. 5a). The comparison with experimental EDP (Fig. 5b) shows that rutile domains indeed deviate from an ideal (101) twin orientation. This can be seen by twisting the twin reflection spots adjacent to the mirror plane and a barely visible splitting of $\{\mathrm{h} 0 \mathrm{~h}\} \mathrm{R}$ reflections related to the mirror plane. As a result the angle between $[002]_{R 1}$ and $[002]_{R \overline{4}}$ across the interface amounts to $\sim 115.4^{\circ}$, which is $\sim 1^{\circ}$ larger than the angle expected for a coherent (101) twin boundary in rutile. HRTEM image recorded on the (101) interface (Fig. 5c) shows that the boundary is disrupted by evenly spaced edge dislocations, separated by $13-$ to $15-\mathrm{nm}$-long sections of more or less undistorted (101)-twin with the characteristic angle of $114.4^{\circ}$ between the $c$-axes. At every dislocation step, an additional $(101)_{R}$ plane is introduced to compensate for the $\sim 1^{\circ}$ mismatch $\left(\theta^{\prime}\right)$. The average length of these sections corresponds to the distance of $d_{(101) R} / \tan \left(\theta^{\prime}\right)=\sim 14 \mathrm{~nm}$ that the rutile structure would need to compensate the mismatch by introducing an extra (101) plane. Such dislocations are never observed on growth twins (Daneu et al. 2014) suggesting that this interface is not a regular twin boundary but rather a result of impingement of two oppositely growing rutile domains.

In the following, we analyze how many different orientations the rutile crystals can adopt with respect to the hematite and how many rutile-rutile relations can consequently be produced. Assuming OR-2, where $(101)_{R}$ is aligned with $(110)_{H}$, the angular difference between the rutile's $c$-axis $[002]_{R}$ and the $b$-axis of hematite $[030]_{H}$ is $2.78^{\circ}$. Tetragonal rutile structure can thus adopt two mirror $( \pm)$ orientations with respect to each of the six $\{110\}_{H}$ planes, leading to 12 possible $H \mid R_{i}$ orientations between hematite and rutile. During growth, rutile domains impinge and can form different types of special grain boundaries, like (101) and (301) twin boundaries (TW), low-angle tilt boundaries (TB) and other semicoherent interfaces. Basically, any of the 12 rutile $R_{i}$ orientations (first set) can meet in any combination with the other 12 rutile $R_{j}$ orientations (2nd set), leading to the total of 144 possible rutile-rutile $R_{i \mid j}( \pm)$ configurations. However, not all permutations represent truly unique configurations. Out of these, 24 configurations reflect into a single crystal orientation, i.e., $R_{i \mid j} j_{i= \pm 1} \ldots 6 ; j= \pm i$ and can be ruled out because they do not produce an interface. Furthermore, half of the remaining variants related to $R_{i \mid j}$ and $\left.R_{j \mid i}\right|_{i= \pm 1} \ldots 6 ; j= \pm 1 \ldots 6$ pairs are identical as they describe the same rutile-rutile configuration; for example, $R_{2 \mid 3} \equiv R_{3 \mid 2}$. All the remaining 60 configurations are unique and could be observed in hematite. For example, six unique (101) twin orientations (related by $60^{\circ}$ rotation) with respect to fixed hematite $(H)$ matrix are possible (illustrated in the inset of Fig. 3c). Disregarding the rotational variants, we can identify four major groups of rutile-rutile relations: (1) (301) twin configuration TW-I at $\varphi_{\text {TW-I }}=54.44^{\circ}$ (6) and complementary TW-I' at $\varphi^{\prime}{ }_{\text {TW-I }}=125.56^{\circ}$ (6), (2) symmetry-related configurations TB-I at $\varphi_{\mathrm{TB}-\mathrm{I}}=60^{\circ}$ (12) and their complementaries TB-I' at $\varphi \mathrm{c}_{\mathrm{TB}-\mathrm{I}}=120^{\circ}$ (12), (3) (101) twin configuration TW-II at $\varphi_{\text {TW-II }}=114.44^{\circ}(6)$ and complementary TW-II' ${ }^{\prime}$ at $\varphi^{\prime}{ }_{\text {TW-II }}=65.56^{\circ}$ (6) and finally (4) low-angle tilt configuration TB-II at $\varphi_{\mathrm{TB}-\mathrm{II}}=174.44^{\circ}$ (6) with complementary TB-II' at $\varphi^{\prime}{ }_{\text {TB-II }}=5.56^{\circ}(6)$. As a result, we can observe eight structurally different $R_{i \mid j}$ interfaces in OR-2, comprising four primary and complementary pairs. A complete list of rutile-rutile configurations $\left(\left.R_{i \mid j}\right|_{i, j= \pm 1} \ldots 6\right)$ with the corresponding tilt angles $(\varphi)$ between the rutile $c$-axes is given in Table 1 . To facilitate identification of $R_{i \mid j}$ duplicates, the angles are given in the range from $0^{\circ}$ to $180^{\circ}$, measured clockwise $R_{i} \rightarrow R_{j}(+)$ if $\varphi<180^{\circ}$, and in counterclockwise direction $R_{i} \leftarrow R_{j}(-)$ if $\varphi>180^{\circ}$ $\left(\bar{\varphi}=360^{\circ}-\varphi\right)$.

Figure 6 shows four of the 60 unique $R_{i \mid j}$, produced by random impingement of the exsoluting rutile lamellae. Here, we observe an extended elbowed band of rutile crossing hematite crystal in the thin part of the sample. Every kink in the band indicates that the rutile changed its orientation with respect to the hematite matrix. Diffraction patterns from each individual rutile domain show that c-axes of rutile domains correspond to four successive $H \mid R_{i}$ orientations $(i=1,2,3$, 4; see illustration in the upper left corner of Fig. 6a with 12 possible $H \mid R_{i}$ ). Small tilt angles between $H \mid R_{1}$ versus $H \mid R_{2}$ and $H \mid R_{3}$ versus $H \mid R_{4}$ produce two different low-angle TB-II, $R_{2 \mid \overline{1}}$ and $R_{4 \mid \overline{3}}$, respectively. Even more interesting is the interface between $H \mid R_{2}$ and $H \mid R_{3}$, where we would expect a short TW-I' interface to minimize the contact area between two differently oriented rutile domains. Instead, a long TW-I boundary $R_{\overline{2}} \mid \overline{3}$ is established. The resulting (301)-twin interface is about five times longer than it would be had its complementary formed. This indicates that a coherent twin boundary has a considerably lower interface energy than the complementary incoherent interface. From above, an additional rutile lamella in yet another $H \mid R_{i}$ orientation joins the main exsolution band. It belongs to the last of the six possible ( \pm ) exsolution directions $H \mid R_{6}$ and coincides with the $H \mid R_{3}$ lamella to form an (101)-twin interface $R_{\overline{6} \mid 3}$. In the close-up of this coincidence situation (Fig. 6b), one can see that the (-) pole of $\mathrm{R}_{6}$ forms (101)-twin with (+) pole of $R_{3}$, and (-) pole of $R_{3}$ forms (301)-twin with (-) pole of $R_{2}$. The corresponding angular relations for particular configurations are listed in Table 1. 
Table 1 A list of hypothetical rutile-rutile configurations that can form during impingement of growing rutile lamellae within the parent hematite crystal based on OR-2

\begin{tabular}{|c|c|c|c|c|c|c|c|c|c|c|c|c|}
\hline $\mathrm{i} \mid \mathrm{j}$ & 1 & 2 & 3 & 4 & 5 & 6 & $\overline{1}$ & $\overline{2}$ & $\overline{3}$ & $\overline{4}$ & $\overline{5}$ & $\overline{6}$ \\
\hline 1 & $\begin{array}{c}\mathrm{R}_{1 \mid 1} \\
0^{\circ}\end{array}$ & $\begin{array}{l}R_{1 \mid 2} \\
5.56^{\circ}\end{array}$ & $\begin{array}{c}\mathrm{R}_{1 \mid 3} \\
60^{\circ}\end{array}$ & $\begin{array}{c}\mathrm{R}_{1 \mid 4} \\
65.56^{\circ}\end{array}$ & $\begin{array}{l}R_{1 \mid 5} \\
120^{\circ}\end{array}$ & $\begin{array}{c}R_{1 \mid 6} \\
125.56^{\circ}\end{array}$ & $\begin{array}{l}R_{1 \mid \overline{1}} \\
180^{\circ}\end{array}$ & $\begin{array}{c}R_{1 \mid \overline{2}} \\
-174.44^{\circ}\end{array}$ & $\begin{array}{l}R_{1 \mid \overline{3}} \\
-120^{\circ}\end{array}$ & $\begin{array}{c}R_{1 \mid \overline{4}} \\
-114.44^{\circ}\end{array}$ & $\begin{array}{l}R_{1 \mid \overline{5}} \\
-60^{\circ}\end{array}$ & $\begin{array}{c}R_{1 \mid \overline{6}} \\
-54.44^{\circ}\end{array}$ \\
\hline 2 & $\begin{array}{l}\mathrm{R}_{2 \mid 1} \\
-5.56^{\circ}\end{array}$ & $\begin{array}{c}\mathrm{R}_{2 \mid 2} \\
0^{\circ}\end{array}$ & $\begin{array}{c}\mathrm{R}_{2 \mid 3} \\
54.44^{\circ}\end{array}$ & $\begin{array}{c}\mathrm{R}_{2 \mid 4} \\
60^{\circ}\end{array}$ & $\begin{array}{c}R_{2 \mid 5} \\
114.44^{\circ}\end{array}$ & $\begin{array}{l}R_{2 \mid 6} \\
120^{\circ}\end{array}$ & $\begin{array}{c}R_{2 \mid \overline{1}} \\
174.44^{\circ}\end{array}$ & $\begin{array}{l}R_{2 \mid \overline{2}} \\
180^{\circ}\end{array}$ & $\begin{array}{c}R_{2 \mid \overline{3}} \\
-125.56^{\circ}\end{array}$ & $\begin{array}{l}R_{2 \mid \overline{4}} \\
-120^{\circ}\end{array}$ & $\begin{array}{c}R_{2 \mid \overline{5}} \\
-65.56^{\circ}\end{array}$ & $\begin{array}{l}R_{2 \mid \overline{6}} \\
-60^{\circ}\end{array}$ \\
\hline 3 & $\begin{array}{l}R_{3 \mid 1} \\
-60^{\circ}\end{array}$ & $\begin{array}{c}R_{3 \mid 2} \\
-54.44^{\circ}\end{array}$ & $\begin{array}{c}\mathrm{R}_{3 \mid 3} \\
0^{\circ}\end{array}$ & $\begin{array}{l}R_{3 \mid 4} \\
5.56^{\circ}\end{array}$ & $\begin{array}{c}\mathrm{R}_{3 \mid 5} \\
60^{\circ}\end{array}$ & $\begin{array}{c}R_{3 \mid 6} \\
65.56^{\circ}\end{array}$ & $\begin{array}{l}R_{3 \mid \overline{1}} \\
120^{\circ}\end{array}$ & $\begin{array}{c}R_{3 \mid \overline{2}} \\
125.56^{\circ}\end{array}$ & $\begin{array}{l}R_{3 \mid \overline{3}} \\
180^{\circ}\end{array}$ & $\begin{array}{c}R_{3 \mid \overline{4}} \\
-174.44^{\circ}\end{array}$ & $\begin{array}{l}R_{3 \mid \overline{5}} \\
-120^{\circ}\end{array}$ & $\begin{array}{c}R_{3 \mid \bar{\sigma}} \\
-114.44^{\circ}\end{array}$ \\
\hline 4 & $\begin{array}{c}R_{4 \mid 1} \\
-65.56^{\circ}\end{array}$ & $\begin{array}{l}R_{4 \mid 2} \\
-60^{\circ}\end{array}$ & $\begin{array}{l}R_{4 \mid 3} \\
-5.56^{\circ}\end{array}$ & $\begin{array}{c}\mathrm{R}_{4 \mid 4} \\
0^{\circ}\end{array}$ & $\begin{array}{c}\mathrm{R}_{4 \mid 5} \\
54.44^{\circ}\end{array}$ & $\begin{array}{c}\mathrm{R}_{4 \mid 6} \\
60^{\circ}\end{array}$ & $\begin{array}{c}R_{4 \mid \overline{1}} \\
114.44^{\circ}\end{array}$ & $\begin{array}{l}R_{4 \mid \overline{2}} \\
120^{\circ}\end{array}$ & $\begin{array}{c}R_{4 \mid \overline{3}} \\
174.44^{\circ}\end{array}$ & $\begin{array}{l}R_{4 \mid \overline{4}} \\
180^{\circ}\end{array}$ & $\begin{array}{c}R_{4 \mid \overline{5}} \\
-125.56^{\circ}\end{array}$ & $\begin{array}{l}R_{4 \mid \bar{\sigma}} \\
-120^{\circ}\end{array}$ \\
\hline 5 & $\begin{array}{l}R_{5 \mid 1} \\
-120^{\circ}\end{array}$ & $\begin{array}{c}R_{5 \mid 2} \\
-114.44^{\circ}\end{array}$ & $\begin{array}{l}R_{5 \mid 3} \\
-60^{\circ}\end{array}$ & $\begin{array}{c}R_{5 \mid 4} \\
-54.44^{\circ}\end{array}$ & $\begin{array}{c}\mathrm{R}_{5 \mid 5} \\
0^{\circ}\end{array}$ & $\begin{array}{l}R_{5 \mid 6} \\
5.56^{\circ}\end{array}$ & $\begin{array}{c}R_{5 \mid \overline{1}} \\
60^{\circ}\end{array}$ & $\begin{array}{l}R_{5 \mid \overline{2}} \\
65.56^{\circ}\end{array}$ & $\begin{array}{l}R_{5 \mid \overline{3}} \\
120^{\circ}\end{array}$ & $\begin{array}{c}R_{5 \mid \overline{4}} \\
125.56^{\circ}\end{array}$ & $\begin{array}{l}R_{5 \mid \overline{5}} \\
180^{\circ}\end{array}$ & $\begin{array}{c}R_{5 \mid \bar{\sigma}} \\
-174.44^{\circ}\end{array}$ \\
\hline 6 & $\begin{array}{c}\mathrm{R}_{6 \mid 1} \\
-125.56^{\circ}\end{array}$ & $\begin{array}{l}R_{6 \mid 2} \\
-120^{\circ}\end{array}$ & $\begin{array}{c}\mathrm{R}_{6 \mid 3} \\
-65.56^{\circ}\end{array}$ & $\begin{array}{l}R_{6 \mid 4} \\
-60^{\circ}\end{array}$ & $\begin{array}{r}R_{6 \mid 5} \\
-5.56^{\circ}\end{array}$ & $\begin{array}{c}\mathrm{R}_{6 \mid 6} \\
0^{\circ}\end{array}$ & $\begin{array}{c}\mathrm{R}_{6 \mid \overline{1}} \\
54.44^{\circ}\end{array}$ & $\begin{array}{c}\mathrm{R}_{6 \mid \overline{2}} \\
60^{\circ}\end{array}$ & $\begin{array}{c}R_{6 \mid \overline{3}} \\
114.44^{\circ}\end{array}$ & $\begin{array}{l}\mathrm{R}_{6 \mid \overline{4}} \\
120^{\circ}\end{array}$ & $\begin{array}{c}\mathrm{R}_{6 \mid \overline{5}} \\
174.44^{\circ}\end{array}$ & $\begin{array}{l}R_{6 \mid \bar{\sigma}} \\
180^{\circ}\end{array}$ \\
\hline$\overline{1}$ & $\begin{array}{l}\mathrm{R}_{\overline{1} \mid 1} \\
180^{\circ}\end{array}$ & $\begin{array}{c}R_{\overline{1} \mid 2} \\
-174.44^{\circ}\end{array}$ & $\begin{array}{l}R_{\overline{1} \mid 3} \\
-120^{\circ}\end{array}$ & $\begin{array}{c}\mathrm{R}_{\overline{1} \mid 4} \\
-114.44^{\circ}\end{array}$ & $\begin{array}{l}R_{\overline{1} \mid 5} \\
-60^{\circ}\end{array}$ & $\begin{array}{c}R_{\overline{1} \mid 6} \\
-54.44^{\circ}\end{array}$ & $\begin{array}{c}\mathrm{R}_{\overline{1} \backslash \overline{1}} \\
0^{\circ}\end{array}$ & $\begin{array}{l}R_{\overline{1} \mid \overline{2}} \\
5.56^{\circ}\end{array}$ & $\begin{array}{c}R_{\overline{1} \mid \overline{3}} \\
60^{\circ}\end{array}$ & $\begin{array}{l}\mathrm{R}_{\overline{1} \mid \overline{4}} \\
65.56^{\circ}\end{array}$ & $\begin{array}{l}R_{\overline{1} \mid \overline{5}} \\
120^{\circ}\end{array}$ & $\begin{array}{c}R_{\overline{1} \mid \overline{6}} \\
125.56^{\circ}\end{array}$ \\
\hline$\overline{2}$ & $\begin{array}{c}R_{\overline{2} \mid 1} \\
174.44^{\circ}\end{array}$ & $\begin{array}{l}R_{2 \mid 2} \\
180^{\circ}\end{array}$ & $\begin{array}{c}R_{\overline{2} \mid 3} \\
-125.56^{\circ}\end{array}$ & $\begin{array}{l}R_{\overline{2} \mid 4} \\
-120^{\circ}\end{array}$ & $\begin{array}{c}R_{\overline{2} \mid 5} \\
-65.56^{\circ}\end{array}$ & $\begin{array}{l}R_{\overline{2} \mid 6} \\
-60^{\circ}\end{array}$ & $\begin{array}{l}R_{\overline{2} \mid \overline{1}} \\
-5.56^{\circ}\end{array}$ & $\begin{array}{c}\mathrm{R}_{\overline{2} \mid \overline{2}} \\
0^{\circ}\end{array}$ & $\begin{array}{c}R_{\overline{2} \mid \overline{3}} \\
54.44^{\circ}\end{array}$ & $\begin{array}{c}R_{\overline{2} \mid \overline{4}} \\
60^{\circ}\end{array}$ & $\begin{array}{c}\mathrm{R}_{\overline{2} \mid \overline{5}} \\
114.44^{\circ}\end{array}$ & $\begin{array}{l}R_{\overline{2} \mid \overline{6}} \\
120^{\circ}\end{array}$ \\
\hline$\overline{3}$ & $\begin{array}{l}R_{\overline{3} \mid 1} \\
120^{\circ}\end{array}$ & $\begin{array}{c}R_{\overline{3} \mid 2} \\
125.56^{\circ}\end{array}$ & $\begin{array}{l}R_{\overline{3} \mid 3} \\
180^{\circ}\end{array}$ & $\begin{array}{c}R_{\overline{3} \mid 4} \\
-174.44^{\circ}\end{array}$ & $\begin{array}{l}R_{\overline{3} \mid 5} \\
-120^{\circ}\end{array}$ & \begin{tabular}{|c|}
$R_{\overline{3} \mid 6}$ \\
$-114.44^{\circ}$ \\
\end{tabular} & $\begin{array}{l}R_{\overline{3} \mid \overline{1}} \\
-60^{\circ}\end{array}$ & $\begin{array}{c}\mathrm{R}_{\overline{3} \mid \overline{2}} \\
-54.44^{\circ}\end{array}$ & $\begin{array}{c}R_{\overline{3} \mid \overline{3}} \\
0^{\circ}\end{array}$ & $\begin{array}{l}R_{\overline{3} \mid \overline{4}} \\
5.56^{\circ}\end{array}$ & $\begin{array}{c}R_{\overline{3} \mid \overline{5}} \\
60^{\circ}\end{array}$ & $\begin{array}{l}R_{\overline{3} \mid \overline{6}} \\
65.56^{\circ}\end{array}$ \\
\hline$\overline{4}$ & $\begin{array}{c}\mathrm{R}_{\overline{4} \mid 1} \\
114.44^{\circ}\end{array}$ & $\begin{array}{l}\mathrm{R}_{\overline{4} \mid 2} \\
120^{\circ}\end{array}$ & $\begin{array}{c}R_{\overline{4} \mid 3} \\
174.44^{\circ}\end{array}$ & $\begin{array}{l}\mathrm{R}_{\overline{4} \mid 4} \\
180^{\circ} \\
\end{array}$ & $\begin{array}{c}R_{\overline{4} \mid 5} \\
-125.56^{\circ}\end{array}$ & $\begin{array}{l}R_{\overline{4} \mid 6} \\
-120^{\circ}\end{array}$ & $\begin{array}{c}R_{\overline{4} \mid \overline{1}} \\
-65.56^{\circ}\end{array}$ & $\begin{array}{l}R_{\overline{4} \mid \overline{2}} \\
-60^{\circ}\end{array}$ & $\begin{array}{l}R_{\overline{4} \mid \overline{3}} \\
-5.56^{\circ}\end{array}$ & $\begin{array}{c}\mathrm{R}_{\overline{4} \mid \overline{4}} \\
0^{\circ}\end{array}$ & $\begin{array}{c}R_{\overline{4} \mid \overline{5}} \\
54.44^{\circ}\end{array}$ & $\begin{array}{c}R_{\overline{4} \mid \overline{6}} \\
60^{\circ}\end{array}$ \\
\hline$\overline{5}$ & $\begin{array}{c}R_{5 \mid 1} \\
60^{\circ}\end{array}$ & $\begin{array}{l}R_{512} \\
65.56^{\circ}\end{array}$ & $\begin{array}{l}R_{\overline{5} \mid 3} \\
120^{\circ}\end{array}$ & $\begin{array}{c}R_{5 / 4} \\
125.56^{\circ}\end{array}$ & $\begin{array}{l}R_{5 \mid 5} \\
180^{\circ}\end{array}$ & $\begin{array}{c}R_{5 \mid 6} \\
-174.44^{\circ}\end{array}$ & $\begin{array}{l}R_{\overline{5} \mid \overline{1}} \\
-120^{\circ}\end{array}$ & $\begin{array}{c}R_{\overline{5} \mid \overline{2}} \\
-114.44^{\circ}\end{array}$ & $\begin{array}{l}R_{\overline{5} \mid \overline{3}} \\
-60^{\circ}\end{array}$ & $\begin{array}{c}R_{\overline{5} \mid \overline{4}} \\
-54.44^{\circ}\end{array}$ & $\begin{array}{c}\mathrm{R}_{\overline{5} \mid \overline{5}} \\
0^{\circ}\end{array}$ & $\begin{array}{l}R_{5 \mid \overline{6}} \\
5.56^{\circ}\end{array}$ \\
\hline$\overline{6}$ & $\begin{array}{c}\mathrm{R}_{\overline{6 \mid 1}} \\
54.44^{\circ}\end{array}$ & $\begin{array}{c}\mathrm{R}_{\overline{6} \mid 2} \\
60^{\circ}\end{array}$ & $\begin{array}{c}\mathrm{R}_{\overline{6} \mid 3} \\
114.44^{\circ}\end{array}$ & $\begin{array}{l}R_{\overline{6} \mid 4} \\
120^{\circ}\end{array}$ & $\begin{array}{c}R_{\overline{6} \mid 5} \\
174.44^{\circ}\end{array}$ & $\begin{array}{l}R_{\overline{6} \mid 6} \\
180^{\circ}\end{array}$ & $\begin{array}{c}R_{\overline{6} \mid \overline{1}} \\
-125.56^{\circ}\end{array}$ & $\begin{array}{l}R_{\overline{6} \mid \overline{2}} \\
-120^{\circ}\end{array}$ & $\begin{array}{l}R_{\overline{6} \mid \overline{3}} \\
-65.56^{\circ}\end{array}$ & $\begin{array}{l}\mathrm{R}_{\overline{6} \mid \overline{4}} \\
-60^{\circ}\end{array}$ & $\begin{array}{l}R_{\overline{6} \mid \overline{5}} \\
-5.56^{\circ}\end{array}$ & $\begin{array}{c}\mathrm{R}_{\overline{6} \mid \overline{6}} \\
0^{\circ}\end{array}$ \\
\hline
\end{tabular}

$R_{i \mid j}$ represent 144 possible orientation relations between the rutile crystals with the corresponding angles between the $c$-axes (see Fig. 6a). Individual $R_{i \mid j}$ belong to the following groups highlighted in colors: single crystal orientations $\left(0^{\circ}\right.$ and $\left.180^{\circ}\right)$-gray; symmetry-related configurations $\left(60^{\circ}\right.$ and $120^{\circ}$, representing each other's complementaries $)$ - white; low-angle tilt configurations $\left( \pm 174.44^{\circ}\right.$ with complementaries at $\left.\pm 5.56^{\circ}\right)-$ blue; (101) twin configurations $\left( \pm 114.44^{\circ}\right.$ with complementaries at $\left.\pm 65.56^{\circ}\right)$ — red; and (301) twin configurations $\left( \pm 54.44^{\circ}\right.$ with complementaries at $\left.\pm 125.56^{\circ}\right)$ - green. Complementary configuration is defined by $\varphi^{\prime}=180^{\circ}-\varphi$

Already from Fig. 6, we could see that $H \mid R$ interfaces do not simply coincide with the c-axis of rutile or any of the low-index lattice planes in hematite or rutile. To better understand their structural relation, interfaces were studied at atomic scale. Figure 7 shows a HRTEM image of two rutile domains coinciding at special low-angle TB-II configuration $R_{2 \mid \overline{1}}$ (see Table 1). The interface between the two domains appears as a single crystal, disrupted by an array of dislocations lined along the contact $(002)_{R}$ plane. Uniformly spaced dislocations indicate that there is an inherent misalignment between the two crystals, distinctive for low-angle tilt boundaries. Net Burgers vector around the dislocation cores equals to the length of the rutile $c$-axis; i.e., $\boldsymbol{b}=[001]_{R}$. However, if the interface is scrutinized more carefully, we realize that the misfit is in fact compensated by the introduction of two half$(101)_{R}$ planes, which meet at the dislocation core from the coinciding two domains (see HRTEM image; Fig. 7). The Burgers vector is thus composed of two components $\boldsymbol{b}=\boldsymbol{b}_{1}+\boldsymbol{b}_{2}=1 / 2 \cdot[101]+1 / 2 \cdot[101]$. The energy associated with such dissociation is expected to be lower (Nakamura et al. 2009) because it involves a combination of two pure edge dislocations in the close-packed (hcp) O-sublattice having shorter Burgers vectors. In addition, this type of dissociation appears to be a quite reasonable solution for symmetric tilt boundaries where the misfit is half compensated by each domain.

The angle enclosed by the $c$-axes for the $R_{2 \mid \overline{1}}$ interface is $174.44^{\circ}$, just short of $180^{\circ}$, which would make up a perfect crystal with no misfit. With an increasing tilt angle $(\theta)$, dislocations start to appear along the interface with the regions of almost perfect crystal inbetween. In our case, the tilt angle is $\theta=2.78^{\circ}$. Now we can calculate the distance that is needed to compensate $1 / 2 \cdot \boldsymbol{b}=d_{(002) R}(0.1479 \mathrm{~nm})$, in one domain, i.e., $D_{\mathrm{TB}-\mathrm{II}}=d_{(002) R} / \tan (\theta)=3.05 \mathrm{~nm}$, which corresponds to the expected distance between dislocations for this interface. The average distance measured from our HRTEM image is larger $\left(D_{\mathrm{TB}-\mathrm{II}}^{\prime}=5.05 \mathrm{~nm}\right)$, indicating that the actual angle between the rutile $c$-axes must be larger. Measured from experimental EDP (Fig. 7), the angle 

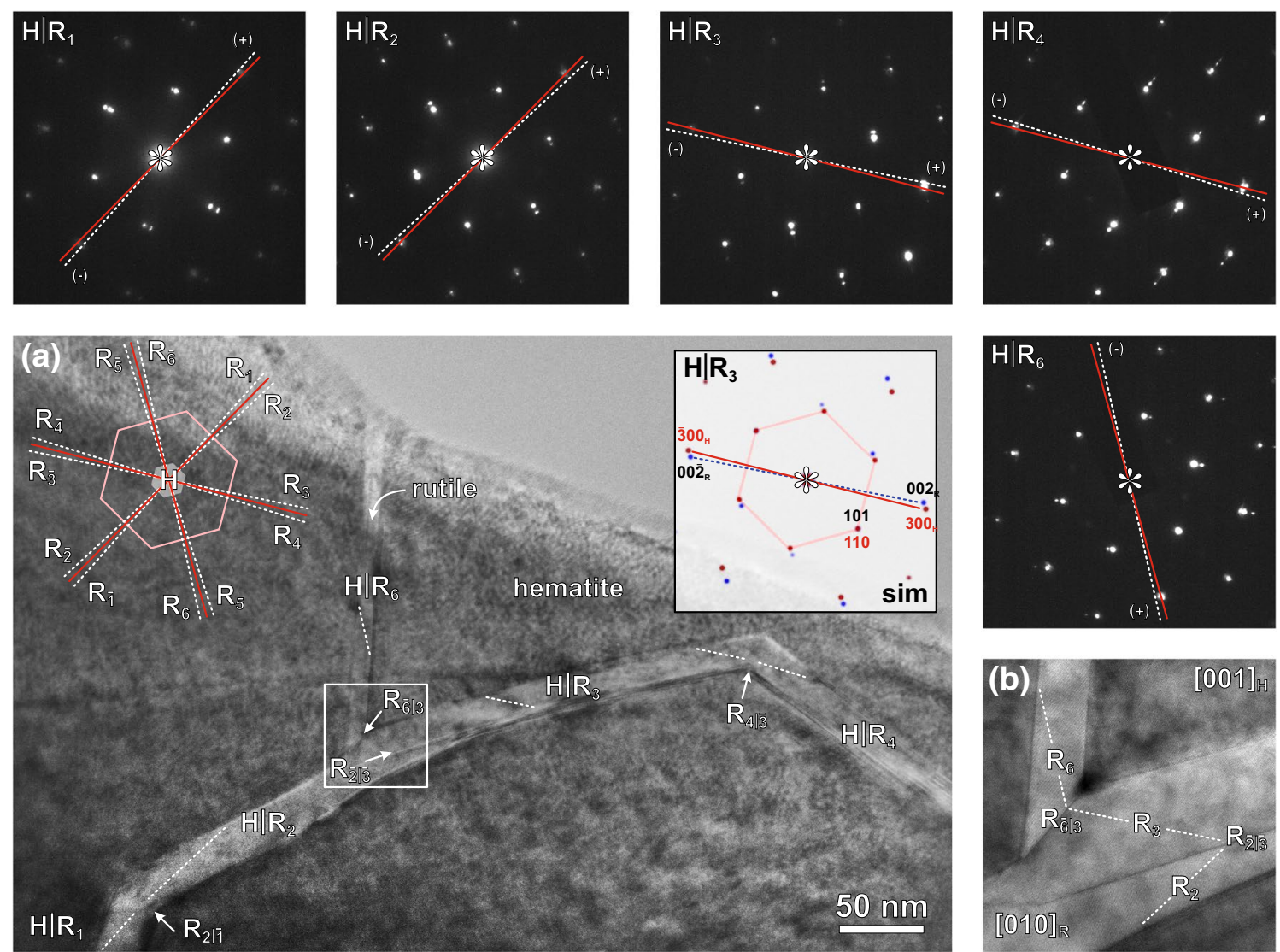

Fig. 6 Crystallographic study of multiple coinciding exsolution lamellae of rutile in hosting hematite matrix. a TEM image of five different hematite/rutile $H \mid R_{i}$ orientations with the corresponding EDP patterns (above and right). In the inset, $H \mid R_{3}$ relationship is simulated to illustrate the coincidence of hematite (red) and rutile (blue) reflections. In total, there are 12 possible $H \mid R_{i}$ orientations of rutile with respect to hematite, according to OR-2, as shown in the drawing in the upper left corner of the TEM image. Red lines indicate six equivalent hematite directions related to its $a$-axis, whereas

between the $c$-axes $[002]_{R 2}$ and $[002]_{R \overline{1}}$ is $\sim 175.5^{\circ}$, which is $\sim 1^{\circ}$ larger than the expected angle for the $R_{2 \mid \overline{1}}$ interface, similar as observed for the $R_{1 \mid \overline{3}}$ interface in Fig. 5. Correspondingly, the actual misorientation tilt angle $\left(\theta^{\prime}\right)$ is somewhat smaller than the one expected by OR-2, which to some extent explains the larger distance between the dislocations, $D_{\mathrm{TB}-\mathrm{II}}^{\prime}$. A half angle between the $R_{2 \mid \overline{1}}$ boundary plane and the $c$-axis (black line in HRTEM image; Fig. 7) measured from the lattice image is $87.8^{\circ}$ and confirms a smaller tilt angle $\theta^{\prime}=2.2^{\circ}$. This small difference $\theta-\theta^{\prime} \approx 0.6^{\circ}$ has the same sense as that on the (101)-twin interface (Fig. 5a) and violates the OR-2.

Let us now focus on the hematite/rutile phase boundary. The interface between the two minerals is perfectly coherent with no apparent misfit dislocations. Based on OR-2, one would anticipate that $(110)_{H}$ planes of hematite would form a coherent interface with $(101)_{R}$ planes of rutile. white dotted lines show 12 possible $c$-axis orientations of rutile tilted for $\pm 2.78^{\circ}$ from the primary directions of hematite. Between any pair of white dotted lines, different rutile-rutile $R_{i \mid j}$ configurations can be produced as a result of domain impingement. Here, four out of 60 possible configurations can be seen: $R_{2 \mid \overline{1}}$ and $R_{4 / \overline{3}}$ (low-angle tilt boundaries, $\left.174.44^{\circ}\right), R_{\overline{2} \mid \overline{3}}(301)$ twin boundary $\left(54.44^{\circ}\right)$ and $R_{\overline{6} \mid 3}$ (101) twin boundary $\left(114.44^{\circ}\right)$. b Close-up of neighboring (101) and (301) interfaces from the central part of (a)

However, the crystals choose different lattice planes. If $(110)_{H}$ lattice planes are viewed across the $H \mid R_{2}$ interface, the equivalent planes in the rutile lattice are deflected for a small angle, which is a result of tetragonal deformation of the rutile's hcp lattice with respect to hematite. When the same set of planes is followed from hematite across the $H \mid R_{1}$ interface onto the lower rutile domain, they seem to pass the boundary almost smoothly, which is a result of specific tilt setting of rutile domains in $R_{2 \mid \overline{1}}$ configuration. $H \mid R$ interfaces are not bound to any simple low-index plane in either of the two lattices, but are composed of periodic steps in the common O-sublattice. The angle measured from the resultant interface line (outlined red; see Fig. 7), e.g., $H \mid R_{1}$, and the $c_{R}$-axis in the corresponding rutile domain amounts to $\sim 21^{\circ}$. This angle is most closely matched by the $(401)_{R \overline{1}}$ plane, which encloses the angle of $21.2^{\circ}$ with the $c_{R}$-axis, indicating that the terminating 




Fig. 7 Structural analysis of low-angle TB-II configuration and the equilibrium hematite/rutile interface. HRTEM image of low-angle tilt boundary $R_{2 \mid \overline{1}}$ produced between two almost equally oriented rutile domains (central part) in the hematite matrix (above-left). The small misorientation between the domains ( $c$-axes directions are indicated by white dotted lines) is compensated by a series of edge dislocations (marked by arrows). The interface (red line) between hematite and rutile $H \mid R$ is coherent and tilted for $\sim 21^{\circ}$ with respect to the re-

planes in the rutile lattice will belong to the $\{401\}_{R}$ family. Accordingly, the interface plane $(\overline{1} 80)_{H}$, belonging to the $\{170\}_{H}$ family, can be identified in the hematite lattice. As there are no physical lattice planes running normal to the $H \mid R_{1}$ interface, the misfit is best calculated using a linear combination of basic lattice vectors corresponding to interface planes in hematite and rutile. If the interface planes are decomposed to fractions of lattice vectors, i.e., $(401)_{R} \equiv(1 / 1,0,1 / 4)_{R}$ and $(170)_{H} \equiv(1 / 7,1 / 1,0)_{H}$, the distances between the common interface points, $d_{R}$ and $d_{H}$, are given by:

$d_{R}^{2}=a_{R}^{2}+\left(4 \cdot c_{R}\right)^{2}$

and

$d_{H}^{2}=\left[\left(7 \cdot a_{H}\right)^{2}+b_{H}^{2}+2 \cdot\left(7 \cdot a_{H}\right) \cdot b_{H} \cdot \cos (\gamma)\right] / 3$ entrant rutile $c$-axis. In hematite, the plane parallel to the interface corresponds to the $\{170\}_{H}$ family, while in rutile the equivalent plane belongs to the $\{401\}_{R}$ family. EDP (upper right corner) recorded over the hematite and the two rutile domains with composed simulated pattern (below) according to the OR-2 (left) for comparison. The stereogram in the upper left corner illustrates the observed crystallographic relations for the $\mathrm{HIR}_{1}$ interface. Note the matching of $(401)_{R} \|(\overline{1} 180)_{H}$ interface planes, instead of $(101)_{R} \|(110)_{H}$

where $a_{R}=0.45937 \mathrm{~nm}, \quad c_{R}=0.29587 \mathrm{~nm}$; $a_{H}=b_{H}=0.5038 \mathrm{~nm}, \gamma=120^{\circ}$. The calculated values, $d_{R}=1.2695 \mathrm{~nm}$ and $d_{H}=1.2679 \mathrm{~nm}$, indicate that hematite and rutile are almost perfectly matched at this particular interface. Distances, $d_{R}$ and $d_{H}$, correspond to five interatomic distances, $d_{\mathrm{Ti}-\mathrm{Ti}}^{\prime}$ and $d_{\mathrm{Fe}-\mathrm{Fe}}^{\prime}$, projected to the interface from each structure. Hence, the misfit $(\delta)$ between the two lattices can be calculated according to the following equation (Löffler and Mader 2003):

$\delta=2 \cdot\left|\frac{d_{R}-d_{H}}{d_{R}+d_{H}}\right|$

resulting in the misfit for the $(170)_{H} \mid(401)_{R}$ interface of $\delta=0.13 \%$. The distance between the interface misfit dislocations, i.e., the Vernier period of a misfit $(D)$, is given by the following equation: 


$$
D=\frac{d_{H} \cdot d_{R}}{\left|d_{H}-d_{R}\right|}
$$

If the calculated period is divided by the number of projected interatomic distances, $d_{\mathrm{Ti}-\mathrm{Ti}}^{\prime}$ and $d_{\mathrm{Fe}-\mathrm{Fe}}^{\prime}$, we obtain a length of $\sim 200 \mathrm{~nm}$, which would theoretically be needed to compensate one projected interatomic distance of the smaller lattice. The relatively high-index lattice planes in rutile and hematite produce an almost ideal coherent interface. Such a small misfit is easily compensated, for example, by relaxation of both lattices, and as a consequence, no misfit dislocations are observed.

As a consequence of matching of $(401)_{R}$ rutile with $(\overline{180})_{H}$ of hematite, the two lattices suffer a slight rotational misalignment of $\theta=0.59^{\circ}$ away from the OR-2, which in a strict sense translates to:

OR-3 : $\langle 010\rangle_{R}\{401\}_{R}||\langle 001\rangle_{H}\{170\}_{H}$.

This can be seen as a slight splitting of the diffraction spots $(110)_{H}$ and $(101)_{R}$ and narrowing the distance between the $\{002\}_{R 2 \mid R \overline{1}}$ pairs next to $(300)_{H}$ reflections in the experimental EDP (inset in Fig. 7). This is best seen if experimental EDP is compared to the composed simulated EDP, where $(110)_{H}$ and $(101)_{R}$ are in coinciding position following the OR-2. The $0.59^{\circ}$ splitting of $(110)_{H}$ and $(101)_{R}$ is shown in stereographic projection of $H \mid R_{1}$ interface (stereogram; Fig. 7), where $(401)_{R}$ is aligned with $(180)_{\mathrm{H}}$ as defined by OR-2, slightly redefining all structural relations between the hematite and rutile.

The origin of Ti ions and exsolution processes in rutile/hematite intergrowths

The crystallographic study of the intergrowths has confirmed that the exsolution of rutile is entirely controlled by the hematite matrix. Consequently, one would expect that the source of Ti ions needed for the formation of intrinsic rutile lamellae must be the parent hematite. EDS analyses on different locations show that hematite matrix contains up to 6 at $\%$ of Ti, whereas the rutile domains may contain up to 1 at $\%$ of $\mathrm{Fe}$. However, the distribution and the mode of solute ordering could not be resolved in the $[001]_{H}$ basal projection. To address these questions, the sample was further studied in perpendicular prism orientations, where we find manifold situations, which contribute to better understanding of the rutile exsolution mechanism.

When the samples are viewed in $[100]_{H}$ projection, we find that hematite is densely populated with Ti-rich precipitates undulating along the basal planes of the parent matrix. Figure 8 shows a hematite crystal with numerous, up to $\sim 20 \mathrm{~nm}$ thick, and several-hundred-nanometer-long lens-shaped precipitates. In the close proximity of the exsoluted rutile lamella (see Fig. 8a; top), the precipitates are becoming shorter and thinner until they disappear completely as the hematite/rutile interface is approached regardless the orientation of the rutile lamella. Bulk hematite matrix contains up to $6 \%$ of Ti, depleting gradually to almost pure hematite composition near the hematite/rutile interface. The depletion zone is indicative for diffusion processes that led to excretion of $\mathrm{TiO}_{2}$ building blocks from parent hematite-ilmenite matrix followed by topotaxial nucleation and growth of rutile on structurally compatible lattice planes. Two types of hematite/rutile relations are observed: (1) prismatic with $(030)_{H}(301)_{R}$ interface and (2) basal with (006) ${ }_{H} \mid(020)_{R}$ interface, both obeying OR-2. The interfaces are abrupt, sharp and coherent when scrutinized at the atomic scale. In the first stage of exsolution thin lamellae of rutile nucleate perpendicular to the basal planes of hematite produce long coherent $(030)_{H} \mid(301)_{R}$ interfaces (Fig. 8b), which are a result of ionic transport along the basal planes of hematite. The nucleation is followed by lateral growth of the rutile lamella parallel to basal planes of hematite following the direction of a continuous supply of Ti ions from gradually dissolving Ti-rich precipitates. HRTEM study of the precipitates confirmed that they correspond to ilmenite (Fig. 8c). In addition to gradually smaller ilmenite patches, the region close to the rutile exsolution is full of random diffusion paths (Fig. 8d). A general direction of the diffusion paths points toward the rutile lamella, i.e., roughly parallel to the basal planes of hematite. EDS analysis with nanobeam probe sizes indicated an enrichment of $\mathrm{Ti}$ along the diffusion paths, thus confirming that they might have served as pathways for Ti migration toward the rutile exsolution. Ti migration pathways testify of a dynamic process during cooling the crystal to lower temperatures where the diffusion becomes sluggish and $\mathrm{Ti}$ ions were frozen on their way toward the rutile lamella.

The last of the topotaxial processes takes place in $\mathrm{Fe}$ rich rutile crystals. When rutile domains are observed under TEM conditions, we realize that they are full of internal defects that could be caused by chemistry variations. This is especially prominent in larger rutile lamellae, whereas the thinner appear to be free of such defects. However, in TEM, the phase contrast at lower magnifications is dominated by intense amplitude contrast stemming from beam convergence, thickness dependent intensity extinctions, bend contours and moiré patterns, making identification of phase boundaries difficult. In such cases, STEM mode is the better choice. Using BF-STEM, we can see that the rutile crystals are densely populated by extended defects producing irregular light and dark gray patches, but some appear to be bound to special crystallographic directions of the rutile structure, as shown in Fig. 9. An increased amount of $\mathrm{Fe}$ in these areas is confirmed by Z-contrast STEM (Fig. 9a) and EDS. HRTEM images of reticulated 

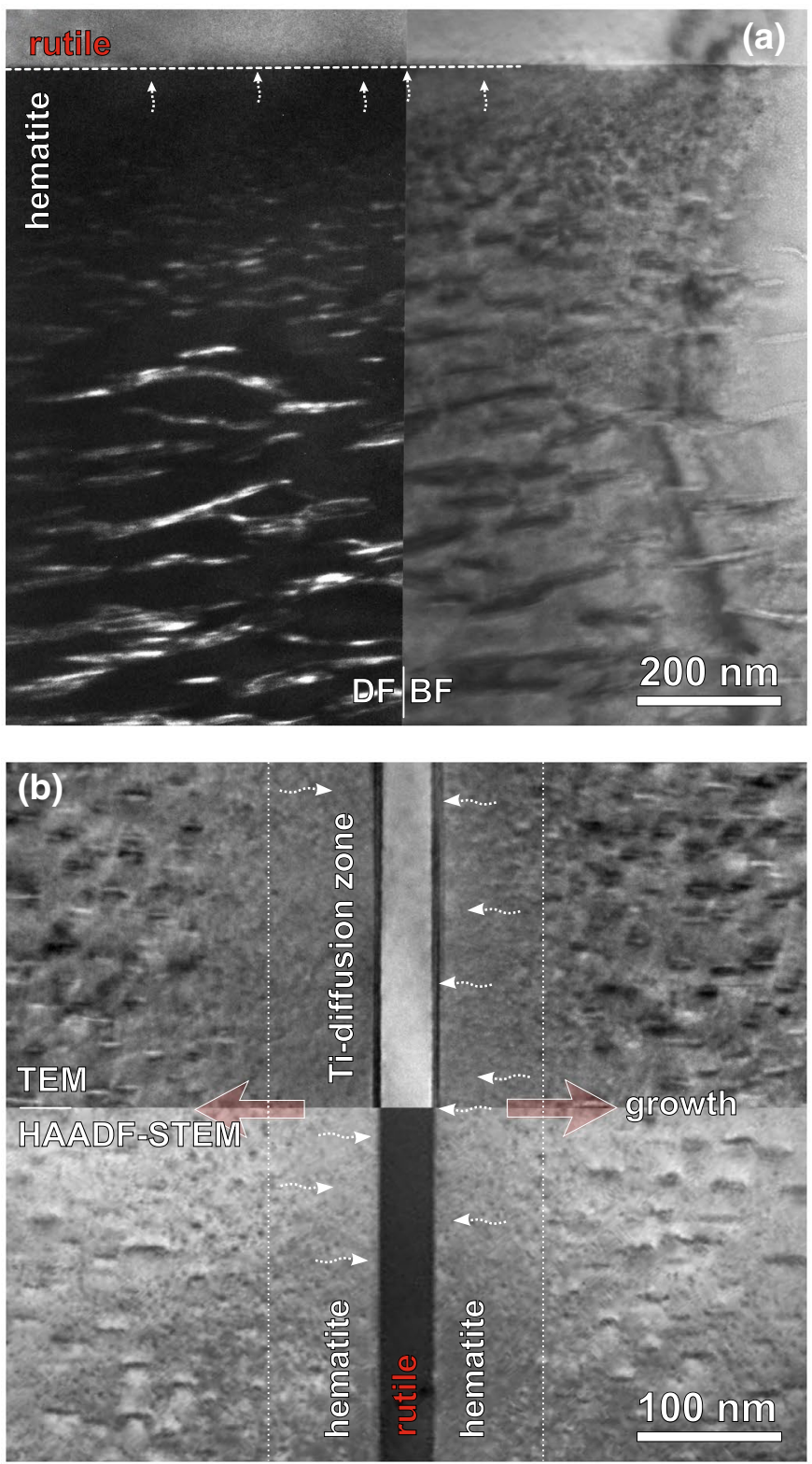

Fig. 8 Rutile/hematite intergrowths viewed along $[100]_{H}$ projection. a Composed bright-field (BF) and dark-field (DF) TEM image of hematite/rutile $(006)_{H}(002)_{R}$ interface with experimental EDP from the boundary region (exp) and simulated EDP (sim) showing crystallographic relation between the two phases. The DF image is produced by long exposure using faint reflections at $\vec{g}=1 / 2 \cdot(006)_{H}$ corresponding to ilmenite. As a result, undulating Ti-rich precipitates appear bright. b Composed TEM/HAADF-STEM image of the $(030)_{H} \mid(301)_{\mathrm{R}}$ interface. White arrows indicate fast diffusion paths for

Fe-rich exsolutions in $[010]_{R}$ projection indicate that they correspond to hematite forming reticulated networks within the parent rutile matrix (Fig. 9b). The width and the length of hematite lamellae are limited by lattice matching in the two growth directions. Diffraction analysis of the hematite lamellae shows that hematite and rutile obey the OR-2 law
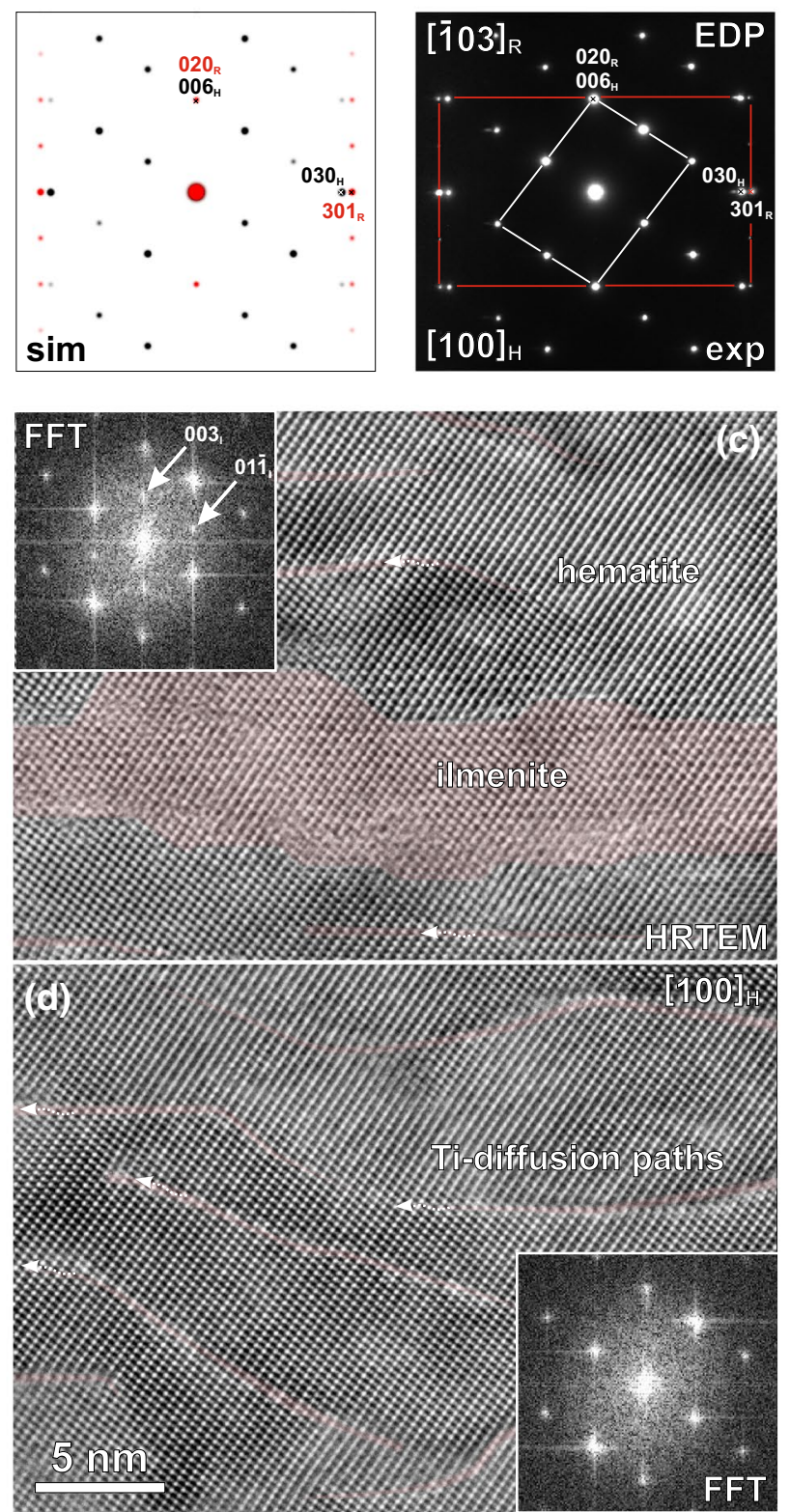

Ti ions, and the red arrows indicate the growth direction of the rutile lamella. c A close-up from Ti-diffusion zone indicated in (b). Deeper in hematite, patches of ilmenite are present in the hosting hematite matrix (above), whereas (d) in the vicinity of the rutile lamella only the Ti-diffusion paths, roughly lined along the hematite basal planes, can be seen (below). Fast Fourier transforms (FFT) from the two regions show the presence or the absence of ilmenite reflections, respectively

(Fig. 9c), while equilibrium interfaces are different than in the case of rutile exsolutions in hematite. Because the misfit between $(101)_{R}$ and $(110)_{H}$ planes is small $(\delta=0.81 \%)$, the lamellae grow without restraint in these directions, forming up to 100 -nm-long coherent $\{301\}_{R} \mid\{030\}_{H}$ interfaces, while the large misfit in perpendicular direction 

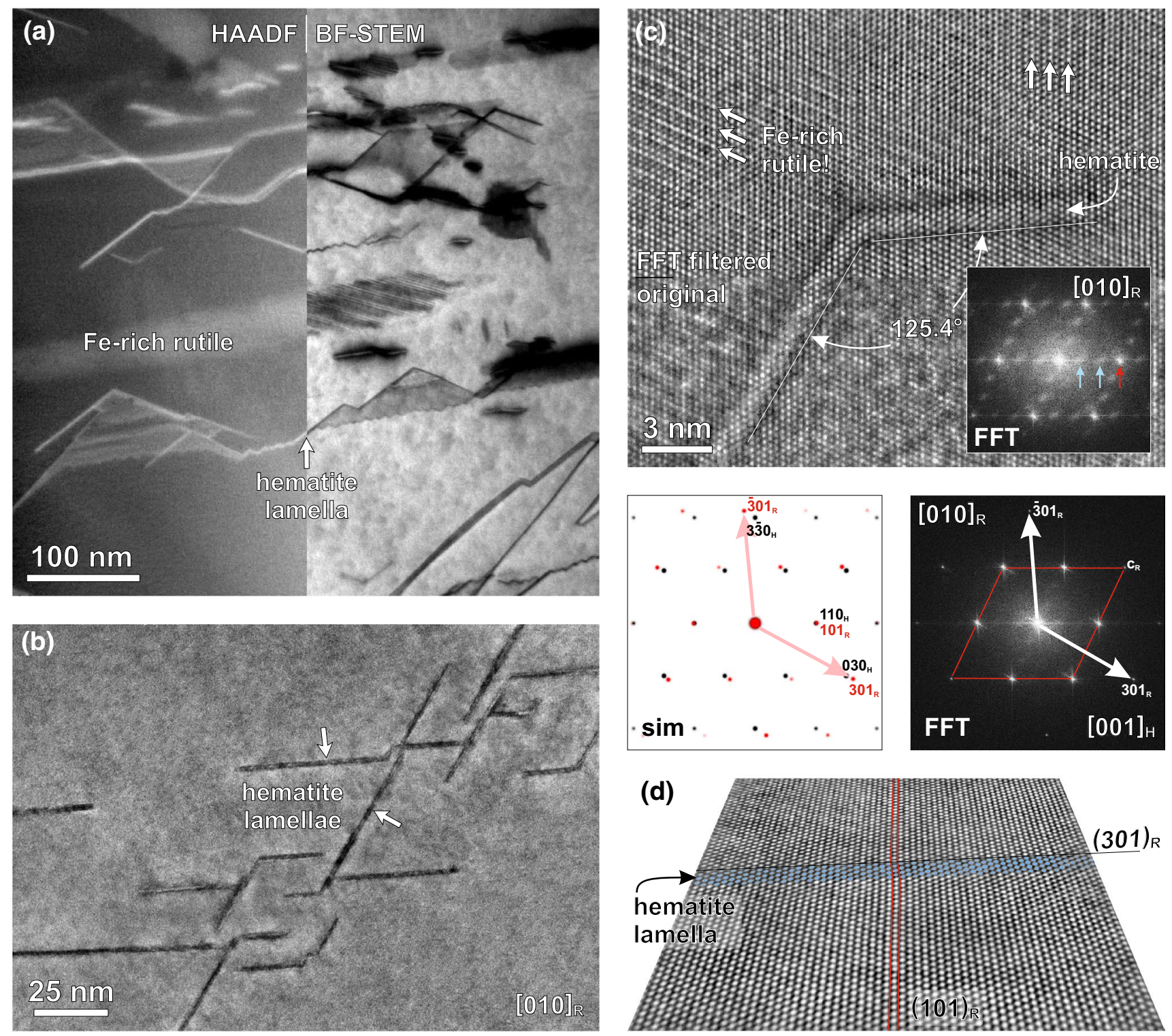

Fig. 9 Fine-scale exsolution of hematite in rutile viewed along $[010]_{R}$ projection. a Composed bright-field (BF) and high-angle annular dark-field (HAADF; $Z$ contrast) STEM image of chemically induced extended defects in rutile. In $Z$ contrast, the defects appear bright, indicating the presence of elements with higher atomic number. b Phase-contrast TEM image of thin reticulate exsolutions of hematite bound to $\{301\}_{R}$ planes. c Close-up of reticulated hema- tite lamella in rutile matrix enclosing an angle of $125.4^{\circ}$. In addition to hematite exsolutions, bulk rutile shows an unusual periodicity at $\vec{g}=1 / 3 \cdot\{101\}_{R}$ (see FFT inset). FFT and simulated EDP show that rutile and hematite obey OR-2, forming coherent $\{301\}_{R} \mid\{030\}_{H}$ interfaces. d Inclined view of hematite lamella (blue) in rutile. (101) ${ }_{R}$ in rutile are deflected by $(110)_{H}$ of hematite with no visible misfit dislocations

\section{Discussion}

Rutile/hematite intergrowths from Mwinilunga are composed of nano- to micro-sized rutile exsolution lamellae interlocked within large idiomorphic hematite single crystals with remnants of lenticular ilmenite precipitates. Rutile and hematite are structurally related through the crystallographic law OR-2, where the $\langle 101\rangle_{R}$ of rutile are lined parallel to $\langle 210\rangle_{H}$ of hematite, which is consistent with temperatures. 
previously reported orientation relationship, determined from morphological relations between the two minerals (Armbruster 1981). The orientation relationship, however, does not provide the necessary information to reconstruct the underlying phase transformation and exsolution mechanism, and for this purpose, phase relations and the nature of equilibrium interfaces that may have been established between intergrown phases need to be studied from macroscopic down to the atomic scale.

Little is known about the origin of these magnificent rutile/hematite intergrowths. According to Tamagnini and Rossi (personal communication), the Mwinilunga intergrowths originate from placer deposits in the Chief Mumena area between the districts of Mwinilunga and Solwezi in NW Zambia, where gabbroic bodies associated with mafic magmatism are reported (Porada and Berhorst 1998). The primary crystals from this locality are thick tabular with a distinct morphology corresponding to the rhombohedral $R \overline{3}$ symmetry. According to Palache et al. (1944), such a habit is characteristic of compositions shifted to ilmenite-rich part of the hematite-ilmenite tieline (Taylor 1963; McEnroe et al. 2005). Ilmenite-rich state of the parent crystals is further substantiated by subnanometer-sized ilmenite precipitates still present in the hosting matrix. Large crystals with ilmenite-rich compositions are distinctive for $\mathrm{Fe}-\mathrm{Ti}$-rich differentiates of mafic and ultramafic magmas (Bateman 1951; Ramdohr 1969). They form isolated discordant bodies emplaced in pegmatitelike dykes, as described in the Bushveld complex (Scoon and Mitchell 1994). Small mafic dykes that also intrude the pre-Katanga basement extending from NW Zambia to Democratic Republic of Kongo (Key et al. 2001) are thus the most likely source of the investigated rutile/hematite intergrowths.

Based on experimental evidences from our study and related literature data, we can reconstruct the sequence of transient processes that took place after the formation of the parent crystals. So, let us start with the primary ilmenite-hematite crystals. The first question that arises is-were they pure ilmenite or a mixture of hematite and ilmenite? As ilmenite and hematite are isostructural, they form complete solid solution (ss) at elevated temperatures (Ishikawa and Akimoto 1958; Burton 1985; McEnroe et al. 2005) through a random substitution of $\mathrm{Fe}^{2+}$ and $\mathrm{Ti}^{4+}$ pairs for two $\mathrm{Fe}^{3+}$ ions preserving the charge balance (Rao and Rao 1965). Typical temperatures estimated for crystallization of ilmenite-hematite series from mafic melts range between 1,050 and $1,150{ }^{\circ} \mathrm{C}$ (Thompson 1976; Nielsen and Dungan 1983; Scoon and Mitchell 1994; Ariskin and Barmina 1999), while their composition depends on oxygen fugacity, $f \mathrm{O}_{2}$ (Buddington and Lindsley 1964), which controls the fraction of $\mathrm{Fe}^{3+}$ ions on crystallization of ferrian-ilmenite (also referred as: hemo-ilmenite). At higher temperatures, the conditions are generally more reducing than at lower temperatures. Hence, at given $f_{2}$, phase compositions at higher temperatures will be shifted toward the ilmenite-rich part of the tie-line. With a decreasing temperature, crystallizing phases are depleted in melts and the composition of crystallizing phases will shift toward the hematite-rich part of the tie-line until the final phase equilibrium is achieved. At this point, $f \mathrm{O}_{2}$ reaches its equilibrium level in the surrounding fluids (Carmichael and Nichols 1967). In our sample, the starting composition of the parent crystal can be roughly estimated from the rutile/ hematite ratio in the interior of the samples. Analysis of the surface areas corresponding to either rutile or hematite from SEM images showed that they coexist in $\sim 1: 1$ ratio, suggesting that the initial composition of the parent crystals was approx. $\mathrm{Ilm}_{67} \mathrm{Hem}_{33}$. Above $900{ }^{\circ} \mathrm{C}$, crystals with this composition form a homogeneous solid solution (Harrison et al. 2000; McEnroe et al. 2005), where $\mathrm{Fe}^{2+}, \mathrm{Fe}^{3+}$ and $\mathrm{Ti}^{4+}$ ions randomly occupy the same type of octahedral interstices in disordered hematite-type structure $(R \overline{3} c)$. At lower temperatures, however, solid solution unmixes into ilmenite $(R \overline{3})$ and hematite $(R \overline{3} c)$ domains by diffusion controlled decomposition (Rao and Rao 1965):

HI: $\left(\mathrm{Fe}_{x}^{2+}, \mathrm{Fe}_{2-2 \cdot x}^{3+}\right) \mathrm{Ti}_{x}^{4+} \mathrm{O}_{3} \rightarrow x \cdot \mathrm{Fe}^{2+} \mathrm{TiO}_{3}+(1-x) \cdot \mathrm{Fe}_{2}^{3+} \mathrm{O}_{3}$

Decomposition is a thermodynamically driven process that can be described as topotaxial precipitation of hematite lamellae in ilmenite matrix, or vice versa, depending on which phase effectively dominates the composition. The size of exsolution domains is determined by the kinetics of the cooling process; during fast cooling, nano-sized lamellae are formed, whereas with slower cooling rate, the size of the lamellae increases. Lamellar texture is typical for ferrian-ilmenite crystals that passed through ilmenitehematite miscibility gap (McEnroe et al. 2005) and would not be present in (e.g., hydrothermally grown) crystals that crystallize below the rhombohedral transition temperature.

Ferrian-ilmenites are described from anorthosites in southern Norway (Ramdohr 1969; Duchesne 1999; Kasama et al. 2003), Saint-Urbain and Allard-Lake in Canada (Carmichael 1961; Morriset et al. 2010) among others (see Haggerty 1971). All these samples originate from mafic rocks, and unlike Mwinilunga, they are not transformed into rutile. Their common feature is that perpendicular to basal planes, ilmenite and hematite display characteristic lamellar structure, whereas in basal sections they appear in form of irregularly shaped patches (Carmichael 1961; Rao and Rao 1965; Ramdohr 1969). Among those, Allard-Lake ferrian-ilmenites (see Fig. 1; Carmichael 1961) with an overall composition of $\mathrm{Ilm}_{70} \mathrm{Hem}_{30}$ seem to best resemble the primary texture of the Mwinilunga parent crystals, that 
is, preserved in fresh parts in the interior of the samples. The lamellar texture of Allard-Lake ferrian-ilmenites was explained as a result of phase separation on slow cooling of the primary solid solution.

In the final stages of crystallization, when the concentration of crystallizing phases is depleted in melt, the remaining volatiles start to act as an external buffer of constant $f \mathrm{O}_{2}$. Here, we reach a crossover stage of crystallization when crystallizing phases no longer control the $f \mathrm{O}_{2}$ but are controlled by it (Carmichael and Nichols 1967). As the temperature is dropping, the activity of oxygen gradually increases to the point where $\mathrm{Fe}^{2+}$ from ilmenite is oxidized to $\mathrm{Fe}^{3+}$ to form hematite and rutile (Carmichael and Nichols 1967; Thompson 1976; Grambling 1986; Zhao et al. 1999):

RHI: $2 \cdot \mathrm{Fe}^{2+} \mathrm{TiO}_{3}+1 / 2 \cdot \mathrm{O}_{2} \rightarrow \mathrm{Fe}_{2}^{3+} \mathrm{O}_{3}+2 \cdot \mathrm{TiO}_{2}$

At first glance, a simple redox reaction triggers complex reorganization of cations in the oxygen sublattice of the parent ferrian-ilmenite host. With a decreasing temperature, chemical potential of oxygen, $\mu \mathrm{O}_{2}$, increases (Grambling 1986). As there are no more mineralizing substances to crystallize, the system no longer follows a particular ferric-ferrous buffer, and the remaining fluids gradually become oxidizing as the activity of oxygen is increased. Oxidation starts at the surface of the ferrian-ilmenite crystal where it is in contact with the oxidizing fluids. Following the oxidation process, surplus $\mathrm{Fe}^{3+}$ ions migrate toward the surface, where they form fresh $\mathrm{Fe}_{2} \mathrm{O}_{3}$ layers, leaving free sites available for the formation of the rutile structure behind. A similar process has been recently reported in thermally treated natural ilmenite (Zhang et al. 2013). The cation redistribution is accomplished within the common hcp oxygen sublattice. In ilmenite, one-third of octahedral sites is occupied by $\mathrm{Ti}^{4+}$ and one-third by $\mathrm{Fe}^{2+}$ cations, whereas in hematite, both two-thirds of octahedral sites are occupied by $\mathrm{Fe}^{3+}$ cations. The remaining octahedral sites in this structure (corundum-type) are empty. In the rutile structure, on the other hand, one half of octahedral sites are occupied by $\mathrm{Ti}^{4+}$ cations and the other half is empty, which makes this structure more vacant compared to the corundum structure. If we assume that all $\mathrm{Ti}^{4+}$ cations from ilmenite are rearranged into rutile-type structure and $\mathrm{Fe}^{3+}$ cations are arranged to form the hematite structure, there is an excess of one-third of $\mathrm{Fe}$ atoms that must leave the structure. This is accomplished through an oxidation process, which offers new sites for accommodation of the excess $\mathrm{Fe}^{3+}$ cations. The empty sites in the oxygen sublattice serve as the pathways for cation migration, as shown by Fe selfdiffusion studies (Amami et al. 1999; Sabioni et al. 2005; Hallström et al. 2011). It has been demonstrated that at higher temperatures, the diffusion of $\mathrm{Fe}$ along the $c$-axis of hematite is several orders of magnitude faster than in prism directions. Fe-diffusion paths established through this process offer convenient sites for exsolution of the rutile. This would explain the formation of pillar-like rutile structures along the $c$-axis of the hosting hematite, observed in prismatic orientation of the Mwinilunga samples (see Fig. 8b). Compared to Fe-diffusion, the Ti-diffusion rates are sluggish (Petersen 1969). It has been reported that Ti-diffusion is most efficient along the basal planes of ferrian-ilmenite (Ishikawa and Syono 1963; Nord and Lawson 1992). Preferred diffusion of $\mathrm{Ti}$ along the basal planes was confirmed by our HRTEM images of Ti-depleted ferrian-ilmenite in the vicinity of the nucleating rutile pillar (Fig. 8d). As the $\mathrm{Ti}$ is less mobile than $\mathrm{Fe}$, this leads to gradual leaching of hematite and its replacement by rutile. Fast Fe-diffusion normal to the basal planes, and slow diffusion of Ti along the basal planes, first leads to nucleation of rutile pillars in vertical direction, which is followed by their progressive growth along the basal planes of the parent ferrian-ilmenite (see Fig. 4). During growth of rutile, released iron can be incorporated in the rutile structure. According to Wittke (1967), rutile may uptake $\sim 1$ at.\% of ferric iron at $800{ }^{\circ} \mathrm{C}$. Throughout the lateral growth of rutile pillars into the hematite matrix, ilmenite lamellae are being gradually dissolved (see remnants of ilmenite; Fig. 8c). In the process of oxidation, the Mwinilunga samples were almost completely converted into rutile and hematite and only a small fraction of ilmenite remained in the interior of the samples $(<1 \%)$.

Let us now take a closer look on the crystallographic aspects of oxidation process. Its complexity depends on reaction kinetics. The overall reaction rate is defined by the following rate-limiting processes: (1) surface oxidation of $\mathrm{Fe}$, (2) rate of Fe-diffusion through hematite crystal, (3) exsolution of rutile with a release of $\mathrm{Fe}$, (4) Ti-diffusion rate through hematite to the rutile/hematite interface and (5) dissolution of ilmenite. Assuming long diffusion paths, the first two processes grossly determine the reaction rateunder low $f \mathrm{O}_{2}$ the reaction is limited by the supply of oxygen and oxidation itself is the rate-limiting process, whereas under high $f \mathrm{O}_{2}$ oxidation is fast and Fe-diffusion becomes the rate-limiting process. At given $p-T$ conditions, the reaction rate is thus controlled by $f_{2}$-when oxygen in the surrounding fluids is present in abundance, all $\mathrm{Fe}$ (probably in form of $\mathrm{Fe}^{2+}$ ) that is supplied by diffusion from the crystal's interior will instantly react to form hematite, whereas in a lack of oxygen all subsequent processes (2-5) are slowed down because of limited surface oxidation. Surface oxidation rate consequently influences the rate of rutile exsolution and controls the mechanism of rutile precipitation. During fast exsolution, rutile assumes simple orientation relationship with respect to parent hematite structure, whereas on slow exsolution it adopts energetically more 
Table 2 Temperature dependence of lattice misfit $(\delta)$ for $(010)_{H} \mid(301)_{R}$ interface (OR-2), (170) $)_{H} \mid(401)_{R}$ interface (OR-3) and $(140)_{H} \mid(501)_{R}$ interface (OR-4) and calculated according to Eq. 6 from lattice parameters of rutile and hematite

\begin{tabular}{llllll}
\hline$T\left({ }^{\circ} \mathrm{C}\right)$ & $\begin{array}{l}\text { Rutile: } a, c \\
(\mathrm{~nm})^{\mathrm{a}}\end{array}$ & $\begin{array}{l}\text { Hematite: } a \\
(\mathrm{~nm})^{\mathrm{b}}\end{array}$ & $\begin{array}{l}\delta_{\mathrm{OR}-2} \\
(\%)\end{array}$ & $\begin{array}{l}\delta_{\mathrm{OR}-3} \\
(\%)\end{array}$ & $\begin{array}{l}\delta_{\mathrm{OR}-4} \\
(\%)\end{array}$ \\
\hline 20 & $0.4593,0.2959$ & 0.5036 & -0.77 & +0.18 & +0.69 \\
250 & $0.4600,0.2965$ & 0.5046 & -0.76 & +0.18 & +0.70 \\
300 & $0.4603,0.2966$ & 0.5049 & -0.79 & +0.15 & +0.67 \\
460 & $0.4608,0.2974$ & 0.5059 & -0.76 & +0.20 & +0.72 \\
600 & $0.4616,0.2977$ & 0.5071 & -0.88 & +0.08 & +0.59 \\
670 & $0.4617,0.2980$ & 0.5080 & -0.94 & +0.02 & +0.54 \\
890 & $0.4625,0.2988$ & 0.5094 & -1.00 & -0.04 & +0.49 \\
1060 & $0.4634,0.2992$ & 0.5108 & -1.13 & -0.17 & +0.36 \\
1190 & $0.4639,0.2997$ & 0.5125 & -1.31 & -0.34 & +0.18 \\
1350 & $0.4645,0.3002$ & 0.5146 & -1.56 & -0.59 & -0.07 \\
1480 & $0.4650,0.3006$ & 0.5162 & -1.74 & -0.77 & -0.25 \\
\hline
\end{tabular}

For OR-3, the best fit between the two lattices is achieved at $\sim 740{ }^{\circ} \mathrm{C}$ and for OR-4 at $\sim 1300{ }^{\circ} \mathrm{C}$

Unit-cell parameters: ${ }^{a}$ Howard et al. (1991), ${ }^{b}$ Nešković et al. (1977), extrapolated $>890{ }^{\circ} \mathrm{C}$. The larger initial values of $\left.\delta\right|_{25^{\circ} \mathrm{C}}$ for OR-3 and OR-4 are due to different data for hematite

favorable relationship. The most simple orientation that the rutile can assume is following the arrays of edge-sharing octahedra of the hematite lattice and continuing the $120^{\circ}$ pattern inherited from the parent lattice. This simple, kinetically driven relationship is known as OR-1 (Armbruster 1981) and was not observed in the Mwinilunga samples. On the other hand, when exsolution is slow, the daughter phase has ample time to establish an equilibrium interface with the parent phase. Under such nucleation conditions, rutile chooses the best matching interface that produces the lowest free energy with hematite under given $p-T$ conditions (Putnis 1978, 1992). As a consequence, topotaxial growth of rutile is controlled by structural coherency between hematite and rutile at the time of its exsolution. The resulting relationship is thus thermodynamically driven and differs from case to case. This type of relationships is best described by OR-2, which roughly corresponds to all rutile/hematite intergrowths in natural samples (Armbruster 1981; Daneu et al. 2007, 2014) and exsolutions of hematite in rutile (Putnis 1978) with small but important deviations that can serve as a precise geothermometer (Banfield and Veblen 1991; Hwang et al. 2010). In the case of rutile exsolutions form Mwinilunga, we showed that rutile and hematite roughly obey the OR-2 law with $0.59^{\circ}$ angular deviation, producing a new OR-3 relationship. This is due to the fact that the crystals adopt unusually high-index habit planes for the equilibrium interface, which in consequence modifies the orientation relationship. Instead of the expected low-index $(010)_{H} \mid(301)_{R}$ interface, which would produce an exact OR-2 (Daneu et al. 2014), we observe a $(170)_{H} \mid(401)_{R}$ interface, making steps composed of lowindex facets at the atomic scale: $3 \cdot(110)_{H}+2 \cdot(\overline{1} 20)_{H}$ and $3 \cdot(200)_{R}+2 \cdot(101)_{R}$. Such interface, in effect, generates even better lattice matching between rutile and hematite. Taking into account unit-cell parameters of ideal rutile (Howard et al. 1991) and hematite (Blake et al. 1966) at ambient conditions, the calculated misfit for this interface is as low as $0.13 \%$. To comprehend the scale of this perfect match, we shall compare our value with the misfits reported in related systems. In (301) twins in rutile, a thin lamella of ilmenite forms a coherent $(100)_{I} I(301)_{R}$ interface with rutile (Daneu et al. 2007), whereas corundum precipitates along (101) twin boundaries in rutile was reported to produce a semicoherent $(110)_{C} \mid(101)_{R}$ interface (Daneu et al. 2014). The misfit values of these interfaces using ideal structures are $\delta_{(100) I(301) R}=1.81 \%$ (Daneu et al. 2007) and $\delta_{(110) C \mid(101) R}=0.53 \%$ (Daneu et al. 2014). If now the misfits are calculated for the equivalent interfaces between hematite and rutile, we obtain $\delta_{(100) H \mid(301) R}=0.81 \%$ and $\delta_{(110) H \mid(101) R}=6.26 \%$, while the lattice matching of $(110)_{H} \mid(101)_{R}$ is poor, that of the $(100)_{H} \mid(301)_{R}$ interface appears relatively good. Instead of choosing either of the two lower-index interfaces with slightly worse fit, hematite and rutile from Mwinilunga obviously prefer a higher-index interface with a lower misfit. Owing to different temperature dependencies of cell parameters, the misfit between hematite and rutile changes with temperature. If the lattice mismatch is calculated as a function of temperature, the optimum matching for our interface is found at $\sim 740{ }^{\circ} \mathrm{C}$, presenting the most probable rutile exsolution temperature for our system (see Table 2). This demonstrates that during slow exsolution, where the system is constantly in nearequilibrium conditions, minimization of interfacial energy is accomplished by perfect match between the two crystal lattices. While particular interface offers the best possible lattice matching between the two structures at given exsolution conditions, faceting and periodic steps are the response of the system to minimize the combined surface energy of the two phases in contact (Bollman 1970).

With a decrease of temperature, the excess of Fe is present in rutile exsolutes in form of hematite nanolamellae (see Fig. 9). The mechanism of hematite exsolution from Fe-bearing rutile was thoroughly studied by Putnis (1978) in the temperature range between 475 and $600{ }^{\circ} \mathrm{C}$. He showed that transformation passes through an intermediate Fe-rich phase possessing high structural coherency with the rutile structure and is characterized by tripling of the rutile's $\{101\}$ diffraction spots associated with $\mathrm{Fe}$ distribution. Based on its structural properties, this intermediate phase was related to Guinier-Preston zones, typical for early stages of precipitation in diverse systems. This is in fact a modulated structure comprising chemical structural 
Fig. 10 Schematic presentation of the progressive transformation of parent hem-ilm $\mathrm{ss}$ precursor crystals into rutile/hematite intergrowths from Mwinilunga. a Parent ferrian-ilmenite (ss) crystal with initial 2:1 ratio between ilmenite and hematite $(x \approx 0.67)$ crystallized in highly differentiated Fe-Ti-rich mafic magma at the temperatures between $1,050^{\circ}$ and $1,150{ }^{\circ} \mathrm{C}$ and $f \mathrm{O}_{2}$ of $10^{-6}-10^{-8}$ bar. At this point, the constituting ions $\mathrm{Ti}^{4+}, \mathrm{Fe}^{3+}$ and $\mathrm{Fe}^{2+}$ are randomly distributed $(R \overline{3}$ c) within the hosting hcp oxygen lattice. b Below $900{ }^{\circ} \mathrm{C}$, hematite $(R \overline{3} c)$ and ilmenite $(R \overline{3})$ are separated and form a characteristic interlayered texture along the basal planes of the structure. $\mathbf{c}$ With a further decrease of temperature, the activity of oxygen present in the surrounding solutions is increased, causing oxidation of ferrous Fe from ilmenite and precipitation of rutile. Owing to fast diffusion rate for Fe along the $c$-axis, its diffusion paths serve as nucleation sites for the formation of rutile pillars. d With progressive oxidation, nucleated rutile pillars grow laterally into the ferrian-ilmenite matrix at the expense of ilmenite layers, which are being dissolved. e In pneumatolitic stage of crystallization, $\mathrm{TiO}_{2}$ from the surrounding solutions recrystallizes on the surface of the samples adopting orientations of the rutile pillars forming faceted, multiply twinned rutile crystals. In this process, some hematite is leached out and recrystallizes in form of Fe-oxyhydroxides in the open pores of the sample. The graphs illustrate $f \mathrm{O}_{2}(\mathrm{~T})$ dependence with a solid line indicating HI-RHI transition according to Eqs. 9 and 10; the exact $f \mathrm{O}_{2}$ is unknown

elements of both end phases and is distinctive of chemically induced transitions between different structures crystallizing within the same sublattice type (Takeuchi 1997; Daneu and Rečnik 2012). Here, we are dealing with a rutile-type structure intercalated with Fe-rich corundum-type layers (Putnis 1978). Characteristic tripling of $\{101\}$ reflections was also confirmed in our samples (Fig. 9c), indicating the same mode of rutile-to-corundum-type structure transformation. Another possibility to explain this contrast feature would be an in-plane orientation of hematite lamellae that could produce a similar interference contrast in this projection. We have shown that the exsolution lamellae of hematite in Mwinilunga rutiles follow the OR-2 law by forming low-index equilibrium $\{301\}_{R} \mid\{030\}_{H}$ interfaces, suggesting exsolution conditions similar to those investigated by Putnis (1978). Hwang et al. (2010) proposed that this may not be the equilibrium interface for this system and suggested that such interfaces would be formed at higher temperatures, where long-range cationic diffusion is possible. This study is particularly interesting from the aspect of diversity of equilibrium interfaces that can be established under different exsolution conditions. Investigating hematite exsolutions in rutiles from ultrahigh-pressure metamorphic rocks (eclogites), formed in the temperature range of 900-1,100 ${ }^{\circ} \mathrm{C}$, they showed that hematite and rutile form high-index equilibrium $(140)_{H} \mid(501)_{R}$ interfaces with lowangle tilt boundaries in exsolved hematite (Fig. 9; Hwang et al. 2010), similar to those observed in reverse case of rutile exsolutions in hematite in our study (Fig. 7). Using same crystal data for hematite (Blake et al. 1966), the calculated misfit for their interface at room temperature is slightly worse than ours and amounts to $0.64 \%$. More
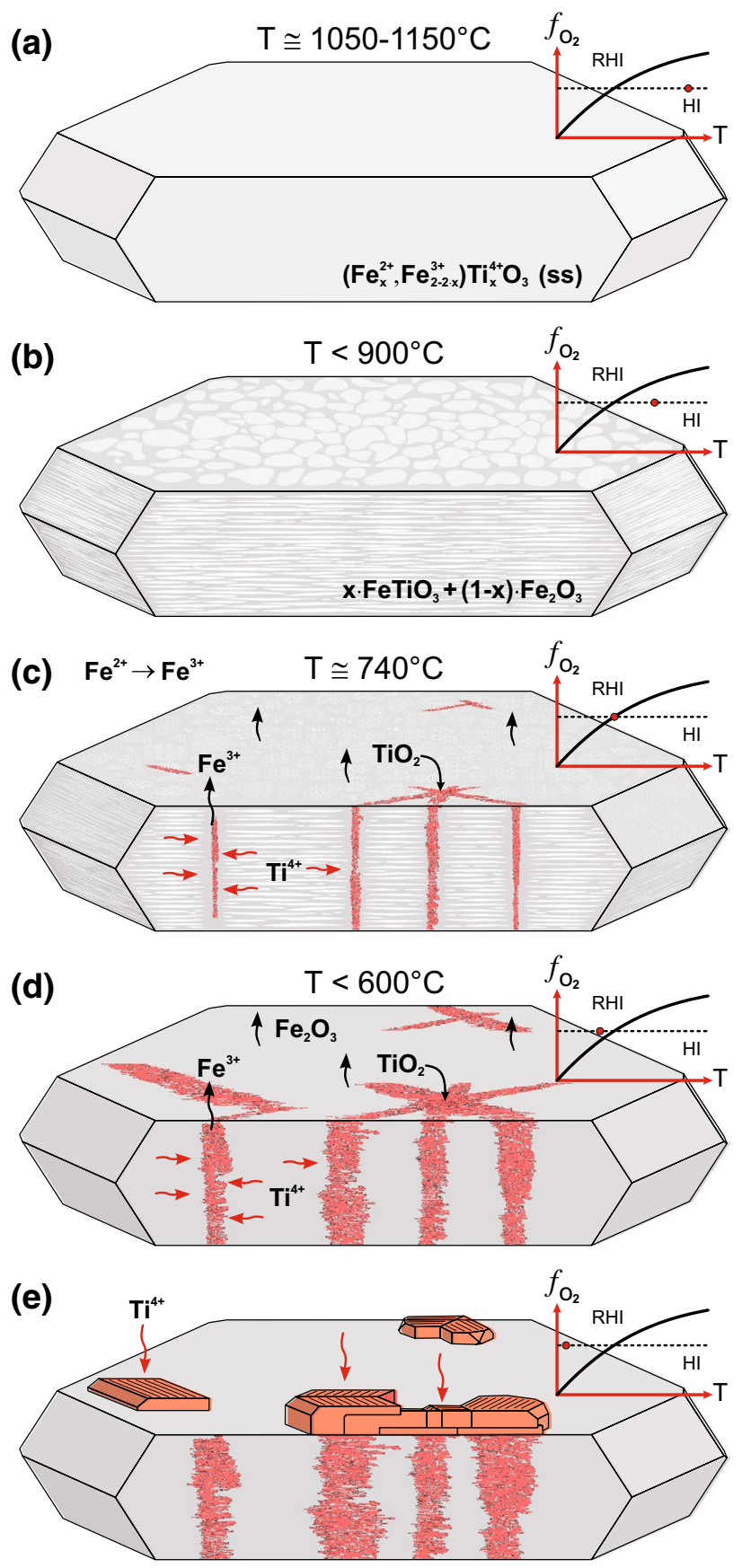

interesting is the comparison of the misfits for the two interfaces as a function of temperature (Table 2), where we can see that our $(170)_{H} \mid(401)_{R}$ interface finds a better match at lower temperatures, whereas the $(140)_{H} \mid(501)_{R}$ interface reported by Hwang et al. (2010) has better matching at higher temperatures, which is consistent with their growth conditions. On the other hand, $(010)_{H} \mid(301)_{R}$ interface of our hematite precipitates in Fe-rich rutile never meet a crossover of lattice matching (see Table 2), supporting the presumption of Hwang et al. (2010) that this is probably not an equilibrium interface. It is important to note that 
the temperatures, estimated from lattice misfits, are only orientational values showing merely the trends where lattice matching is expected to be optimal. For more reliable results regarding the exsolution temperature, the dependence of cell parameters versus temperature should be measured on the particular phase system.

The final stage in the development of rutile/hematite intergrowths is epitaxial growth of the large rutile crystals on basal surfaces of hematite crystals. The growth of the rutile crystals with thick prismatic habit is related to late pneumatolitic phase (Ramdohr 1969). Their orientation is controlled by the exposed rutile domains that extend from the interior of the samples. On recrystallization, $\{101\}$ twin boundaries predominate other interfaces, including the $\{301\}$ boundaries (Fig. 2). This is due to the fact that $\{101\}$ twin boundaries are the most stable interface configuration in rutile (Lee et al. 1993). As the growth of these crystals is unrestrained, they develop crystallographic faces of the lowest surface energy at given $p-T$ conditions. At the end of crystallization, the intergrowths were exposed to superficial hydrothermal solutions which caused hydrolysis of hematite to form Fe-oxyhydroxides (Fig. 4c), indicating that the $\mathrm{pH}$ of the fluids was neutral to alkaline, while acidic conditions would cause rapid leaching of the $\mathrm{Fe}^{3+}$ ions from the crystals (Janssen et al. 2010). The major stages in the formation of rutile/ hematite intergrowths are illustrated in Fig. 10.

\section{Conclusions}

In this work, we studied crystallographic and structural relations between exsoluted crystalline phases in rutile/hematite intergrowths from Mwinilunga in NW Zambia down to the atomic level in order to reconstruct the mechanism of their formation. In the correlation with extensive literature data on phase relations, oxidation reactions, exsolution processes and diffusivities in the $\mathrm{FeO}-\mathrm{TiO}_{2}-\mathrm{Fe}_{2} \mathrm{O}_{3}$ ternary system, all observed topotaxial reactions appear to be a function of temperature and oxygen fugacity, $f \mathrm{O}_{2}$. While the temperature was shown to act as the main trigger of phase transformations, $f \mathrm{O}_{2}$ is responsible for redox reactions, such as oxidation of ferrous $\rightarrow$ ferric iron, which consequently triggers exsolution of rutile. Reconstructed transformation mechanism of Mwinilunga intergrowths comprises five distinctive stages, starting from their formation (see Fig. 10):

(1) The rutile-to-hematite ratio of $\sim 1: 1$ suggests that the composition of the primary ferrian-ilmenite (ss) crystals with a general formula of $\left.\left(\mathrm{Fe}_{\mathrm{x}}^{2+}, \mathrm{Fe}_{2-2 \cdot \mathrm{x}}^{3+}\right) \mathrm{Ti}_{\mathrm{x}}^{4+} \mathrm{O}_{3}\right|_{x=0.67}$ was $\mathrm{Ilm}_{0.67} \mathrm{Hem}_{0.33}$. Crystals in this composition range nucleate at high temperatures $\left(1,050-1,150{ }^{\circ} \mathrm{C}\right.$; Ariskin and Barmina 1999) and low oxygen fugacities $f_{2}$ $\left(10^{-6}-10^{-8}\right.$ bar; Buddington and Lindsley 1964), typical for crystallization from highly differentiated melts in mafic igneous systems. Under these conditions, the $\mathrm{Fe}^{2+}, \mathrm{Fe}^{3+}$ and $\mathrm{Ti}^{4+}$ cations are randomly distributed on the octahedral sites and form a disordered, hematite-like $(R \overline{3} c)$ structure.

(2) Following the $\mathrm{Ilm}_{0.67} \mathrm{Hem}_{0.33}$ solvus, $f \mathrm{O}_{2}$ drops to $\sim 10^{-11}$ bar under $900{ }^{\circ} \mathrm{C}$ where our composition unmixes to hematite and ilmenite (McEnroe et al. 2005). This stage is characterized by the formation of lamellar texture that could still be found in the fresh parts of our samples. Remnants of the exsolution texture strongly indicate that the primary crystals formed in the ilmenite-hematite solid-solution range and would not be present if the crystals formed below the rhombohedral $(R \overline{3} c \rightarrow R \overline{3})$ transition temperature (e.g., hydrothermally grown).

(3) With further decrease of temperature, the concentration of $\mathrm{Fe}^{2+} / \mathrm{Fe}^{3+}$ and $\mathrm{Ti}^{4+}$ ions in the surrounding solutions is depleted, while the activity of oxygen increases to the point where it becomes oxidative. At this stage, $\mathrm{Fe}^{2+}$ from ilmenite is oxidized to $\mathrm{Fe}^{3+}$, leading to exsolution of rutile from the parent ferrian-ilmenite crystal. Owing to the high Fe-diffusivity rates along the $c$-axis (Hallström et al. 2011), the established diffusion channels serve as convenient sites for exsolution of rutile, forming magnificent rutile pillars. Surface oxidation of ferrous iron controls the rate of rutile exsolution, dictating its topotaxial growth in hematite matrix. As a result, this process equilibrium $\{170\}_{H} \mid\{401\}_{R}$ interfaces are formed, leading to 144 different rutile-rutile intergrowths, identified by our structural analysis. The temperature of perfect lattice match for this particular interface is around $740{ }^{\circ} \mathrm{C}$.

(4) Due to preferred diffusion of Ti along the basal planes of the hematite structure (Nord and Lawson 1992), the pillars grow in lateral direction at the expense of dissolving ilmenite. At the temperatures decreasing below $600{ }^{\circ} \mathrm{C}$, the excess iron from Fe-rich rutile lamellae exsolutes in form of reticulated hematite precipitates with $\{301\}_{R} \mid\{030\}_{H}$ equilibrium interfaces, via the modulated Fe-Ti-rich transition phase of GuinierPreston zones (Putnis 1978).

(5) In the late pneumatolitic stage, accompanied by weak dissolution of hematite, rutile recrystallizes on the surface of the samples in form of well-developed crystals adopting the orientation of exposed rutile domains from the interior of the samples. Here, $\{101\}$-twin boundaries are dominating over other possible rutile-rutile interfaces.

Acknowledgments Financial support by the Slovenian Research Agency under the Project No. J1-6742 »Atomic-scale studies of initial stages of phase transformations in minerals« and PhD Grant 
No. 1000-11-310225 is gratefully acknowledged. We thank Fabio Tamagnini (tamagninifabio@interfree.it) from Rome (I) for providing the specimens and valuable information on the locality of the samples. We are grateful to Associate Editor Prof. Dr. Christian Ballhaus from Bonn (D) for his kind suggestions that helped us to improve the manuscript.

Open Access This article is distributed under the terms of the Creative Commons Attribution License which permits any use, distribution, and reproduction in any medium, provided the original author(s) and the source are credited.

\section{References}

Amami B, Addou M, Millot F, Sabioni A, Monty C (1999) Self diffusion in $\alpha-\mathrm{Fe}_{2} \mathrm{O}_{3}$ natural single crystals. Ionics 5:358-370

Ariskin AA, Barmina GS (1999) An empirical model for the calculation of spinel-melt equilibria in mafic igneous systems at atmospheric pressure: 2. Fe-Ti oxides. Contrib Mineral Petrol $134: 251-263$

Armbruster T (1981) On the origin of sagenites: structural coherency of rutile with hematite and spinel structure types. Neues Jb Miner Mn 7:328-334

Banfield JF, Veblen DR (1991) The structure and origin of Fe-bearing platelets in metamorphic rutile. Am Min 76:113-127

Bateman AM (1951) The formation of late magmatic oxide ores. Econ Geol 46:404-426

Blake RL, Hessevick RE, Zoltai T, Finger LW (1966) Refinement of the hematite structure. Am Min 51:23-129

Bollman W (1970) Crystal defects and crystalline interfaces. Springer, Berlin

Buddington AF, Lindsley DH (1964) Iron-titanium oxide minerals and synthetic equivalents. J Petrol 5:310-357

Burton BP (1985) Theoretical analysis of chemical and magnetic ordering in the system $\mathrm{Fe}_{2} \mathrm{O}_{3}-\mathrm{FeTiO}_{3}$. Am Min 70:1027-1035

Carmichael CM (1961) The magnetic properties of ilmenite-hematite crystals. Proc R Soc Lond A 263:508-530

Carmichael CM, Nichols (1967) Iron-titanium oxides and oxygen fugacities in volcanic rocks. J Geophys Res 72:4665-4687

Daneu N, Rečnik A (2012) The atomic-scale aspects of twinning and polytypism in minerals. Acta Mineral Petrogr. Abstract Series 7:32-37

Daneu N, Schmid H, Rečnik A, Mader W (2007) Atomic structure and formation mechanism of (301) rutile twins from Diamantina (Brazil). Am Min 92:1789-1799

Daneu N, Rečnik A, Mader W (2014) Atomic structure and formation mechanism of (101) rutile twins from Diamantina (Brazil). Am Min 99:612-624

Dent Glasser LS, Glasser FP, Taylor HFW (1962) Topotactic reactions in inorganic oxy-compounds. Q Rev Chem Soc 16:343-360

Duchesne JC (1999) Fe-Ti deposits in Rogaland anorthosites (South Norway): geochemical characteristics and problems of interpretation. Miner Deposita 34:182-198

Force ER, Richards RP, Scott KM, Valentine PC, Fishman NS (1996) Mineral intergrowths replaced by 'elbow-twinned' rutile in altered rocks. Can Mineral 34:605-614

Ghiorso MS (1990) Thermodynamic properties of hematite-ilmenitegeikielite solid solutions. Contr Mineral Petrol 104:645-667

Grambling JA (1986) A regional gradient in the composition of metamorphic fluids in pelitic schist, Pecos Baldy, New Mexico. Contrib Mineral Petrol 94:149-164

Haggerty SE (1971) Oxide textures—a mini atlas. In: Lindsley DH (ed) Oxide minerals: petrologic and magnetic significance. Rev Mineral 25:129-219
Hallström S, Höglund L, Ågren J (2011) Modeling of iron diffusion in the iron oxides magnetite and hematite with variable stoichiometry. Acta Mater 59:53-60

Harrison JR, Becker U, Redfern SAT (2000) Thermodynamics of the $R \overline{3}$ to $R \overline{3} c$ phase transition in the ilmenite-hematite solid solution. Am Min 85:1694-1705

Howard CJ, Sabine TM, Dickson F (1991) Structural and thermal parameters for rutile and anatase. Acta Cryst B47:462-468

Hwang SL, Shen P, Yui TH, Chu HT (2010) On the coherency-controlled growth habit of precipitates in minerals. J Appl Cryst 43:417-428

Ishikawa Y, Akimoto S (1958) Magnetic property and crystal chemistry of ilmenite $\left(\mathrm{MeTiO}_{3}\right)$ and hematite $\left(\alpha \mathrm{Fe}_{2} \mathrm{O}_{3}\right)$ system I. Crystal chemistry. J Phys Soc Jpn 13:1110-1118

Ishikawa Y, Syono Y (1963) Order-disorder transformation and reverse thermo-remanent magnetism in the $\mathrm{FeTiO}_{3}-\mathrm{Fe}_{2} \mathrm{O}_{3}$ system. J Phys Chem Solids 24:517-528

Janssen A, Putnis A, Geisler T, Putnis CV (2010) The experimental replacement of ilmenite by rutile in $\mathrm{HCl}$ solutions. Min $\mathrm{Mag}$ 74:633-644

Kasama T, Golla-Schindler U, Putnis A (2003) High-resolution and energy-filtered TEM of the interface between hematite and ilmenite exsolution lamellae: relevance to the origin of the lamellar magnetism. Am Min 88:1190-1196

Key RM, Liyungu AK, Njamu FM, Somwe V, Banda J, Mosley PN, Armstrong RA (2001) The western arm of the Lufilian Arc in NW Zambia and its potential for copper mineralization. J Afr Earth Sci 33:503-528

Lee WY, Bristowe PD, Gao Y, Merkle KL (1993) The atomic structure of twin boundaries in rutile. Philos Mag Lett 68:309-314

Lindh A (1972) A hydrothermal investigation of the system FeO, $\mathrm{Fe}_{2} \mathrm{O}_{3}, \mathrm{TiO}_{2}$. Lithos 5:325-343

Lindsley DH (1973) Delimitation of the hematite-ilmenite miscibility gap. Geol Soc Am Bull 84:657-662

Lindsley DH (1991) Experimental studies of oxide minerals. In: Lindsley DH (ed) Oxide minerals: petrologic and magnetic significance. Rev Mineral 25:69-106

Löffler L, Mader W (2003) Transformation mechanism of the dehydration of diaspore. J Am Ceram Soc 86:534-540

McEnroe SA, Harrison RJ, Jackson MJ, Hirt AM, Peter Robinson P, Langenhorst F, Heidelbach F, Kasama T, Putnis A, Brown LL, Golla-Schindler U (2005) Lamellar magnetism: Effects of interface versus exchange interactions of nanoscale exsolutions in the ilmenite-hematite system. J Phys: Conf Ser 17:154-167

Meinhold G (2010) Rutile and its applications in earth sciences. Earth Sci Rev 102:1-28

Morriset CE, Scoates JS, Weis D, Sauvé M, Stanaway KJ (2010) Rutile-bearing ilmenite deposits associated with the Proterozoic Saint-Urbain and Lac Allard anorthosite massifs, Grenville province, Quebec. Can Min 48:821-849

Nakamura A, Tochigi E, Shibata N, Yamamoto T, Ikuhara Y (2009) Structure and configuration of boundary dislocations on low angle tilt grain boundaries in alumina. Mater Trans, JIM 50:1008-1014

Nešković NB, Babić B, Konstantinović J (1977) High temperature anomalous behavior of the crystal lattice of hematite. Phys Stat Sol 41:K133-K136

Nielsen RL, Dungan MA (1983) Low pressure mineral-melt equilibria in natural anhydrous mafic systems. Contrib Mineral Petrol 84:310-326

Nord GL, Lawson CA (1992) Magnetic properties of ilmentite ${ }_{70}$-hematite $_{30}$ : effect of transformation-induced twin boundaries. J Geophys Res 97:10897-10910

Palache C, Berman H, Frondel C (1944) The system of mineralogy. Vol. I-elements, sulfides, sulfosalts and oxides, 7th edn. Wiley, London 
Petersen N (1969) Calculation of diffusion coefficient and activation energy of titanium in titanomagnetite. Phys Earth Planet Interiors 2:175-178

Porada H, Berhorst V (1998) Thrust tectonics in the domes region and copperbelt of Zambia: outline and outlook. Freib Forschungsh C475:145-162

Putnis A (1978) The mechanism of exsolution of hematite from ironbearing rutile. Phys Chem Minerals 3:183-197

Putnis A (1992) An introduction to mineral sciences. Cambridge University Press, Cambridge

Ramdohr P (1969) The ore minerals and their intergrowths, 3rd edn. Pergamon Press Ltd., London

Rao NK, Rao GVU (1965) Intergrowths in ilmenite of the beach sands of Kerala. Miner Mag 35:118-130

Sabioni ACS, Huntz AM, Daniel AMJM, Macedo WAA (2005) Measurement of iron self-diffusion in hematite single crystals by secondary ion-mass spectrometry (SIMS) and comparison with cation self-diffusion in corundum-structure oxides. Philos Mag 85:3643-3658
Scoon RN, Mitchell AA (1994) Discordant iron-rich ultramafic pegmatites in the Bushveld Complex and their relationship to ironrich intercumulus and residual liquids. J Petrol 35:881-917

Takeuchi Y (1997) Tropochemical cell-twinning: a structure-building mechanism in crystalline solids. Terra Scientific Publishing Company, Tokyo

Taylor RW (1963) Liquidus temperatures in the system $\mathrm{FeO}-\mathrm{Fe}_{2} \mathrm{O}_{3}-$ $\mathrm{TiO}_{2}$. J Am Ceram Soc 46:276-279

Thompson RN (1976) Chemistry of ilmenites crystallized within the anhydrous melting range of a tholeiitic andesite at pressures between 5 and $26 \mathrm{~kb}$. Min Mag 40:857-862

Wittke JP (1967) Solubility of iron in $\mathrm{TiO}_{2}$ (rutile). J Am Ceram Soc 50:586-588

Zhang J, Zhu Q, Xie Z, Lei C, Li H (2013) Morphological changes of Panzhihua ilmenite during oxidation treatment. Metall Mater Trans B 44B:897-905

Zhao D, Essene EJ, Zhang Y (1999) An oxygen barometer for rutileilmenite assemblages: oxidation state of metasomatic agents in the mantle. Earth Planetary Sci 166:127-137 